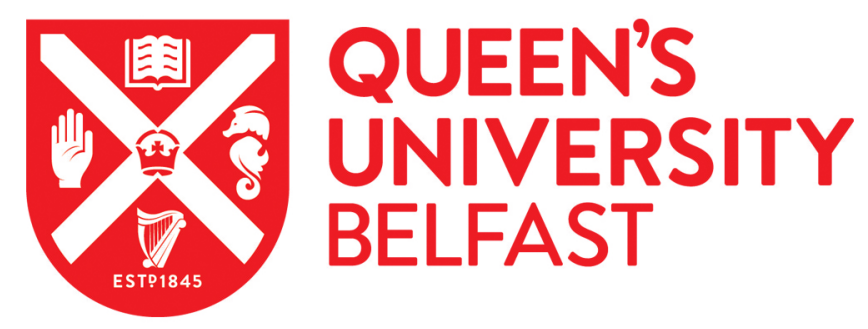

\title{
Universal tight binding model for chemical reactions in solution and at surfaces. III. Stoichiometric and reduced surfaces of titania and the adsorption of water
}

\author{
Lozovoi, A. Y., Pashov, D. L., Sheppard, T. J., Kohanoff, J. J., \& Paxton, A. T. (2014). Universal tight binding \\ model for chemical reactions in solution and at surfaces. III. Stoichiometric and reduced surfaces of titania and \\ the adsorption of water. Journal of Chemical Physics, 141(4), [044505]. https://doi.org/10.1063/1.4890492
}

Published in:

Journal of Chemical Physics

Document Version:

Publisher's PDF, also known as Version of record

Queen's University Belfast - Research Portal:

Link to publication record in Queen's University Belfast Research Portal

\footnotetext{
Publisher rights

Copyright 2014 AIP Publishing. This article may be downloaded for personal use only. Any other use requires prior permission of the author and AIP Publishing.

The following article appeared in The Journal of Chemical Physics and may be found at

http://scitation.aip.org/content/aip/journal/jcp/141/4/10.1063/1.4890492
}

\section{General rights}

Copyright for the publications made accessible via the Queen's University Belfast Research Portal is retained by the author(s) and / or other copyright owners and it is a condition of accessing these publications that users recognise and abide by the legal requirements associated with these rights.

\section{Take down policy}

The Research Portal is Queen's institutional repository that provides access to Queen's research output. Every effort has been made to ensure that content in the Research Portal does not infringe any person's rights, or applicable UK laws. If you discover content in the

Research Portal that you believe breaches copyright or violates any law, please contact openaccess@qub.ac.uk. 


\section{A|P|l $\begin{aligned} & \text { The Journal of } \\ & \text { Chemical Physics }\end{aligned}$}

Universal tight binding model for chemical reactions in solution and at surfaces. III. Stoichiometric and reduced surfaces of titania and the adsorption of water

A. Y. Lozovoi, D. L. Pashov, T. J. Sheppard, J. J. Kohanoff, and A. T. Paxton

Citation: The Journal of Chemical Physics 141, 044505 (2014); doi: 10.1063/1.4890492

View online: http://dx.doi.org/10.1063/1.4890492

View Table of Contents: http://scitation.aip.org/content/aip/journal/jcp/141/4?ver=pdfcov

Published by the AIP Publishing

\section{Articles you may be interested in}

Universal tight binding model for chemical reactions in solution and at surfaces. II. Water

J. Chem. Phys. 141, 044504 (2014); 10.1063/1.4890343

Universal tight binding model for chemical reactions in solution and at surfaces. I. Organic molecules J. Chem. Phys. 141, 044503 (2014); 10.1063/1.4887095

Transition metal atoms pathways on rutile TiO2 (110) surface: Distribution of Ti3+ states and evidence of enhanced peripheral charge accumulation

J. Chem. Phys. 138, 154711 (2013); 10.1063/1.4801025

Density functional theory study of water adsorption at reduced and stoichiometric ceria (111) surfaces

J. Chem. Phys. 125, 204704 (2006); 10.1063/1.2400034

Multilayer adsorption of water at a rutile TiO $2(110)$ surface: Towards a realistic modeling by molecular dynamics J. Chem. Phys. 121, 3722 (2004); 10.1063/1.1772752

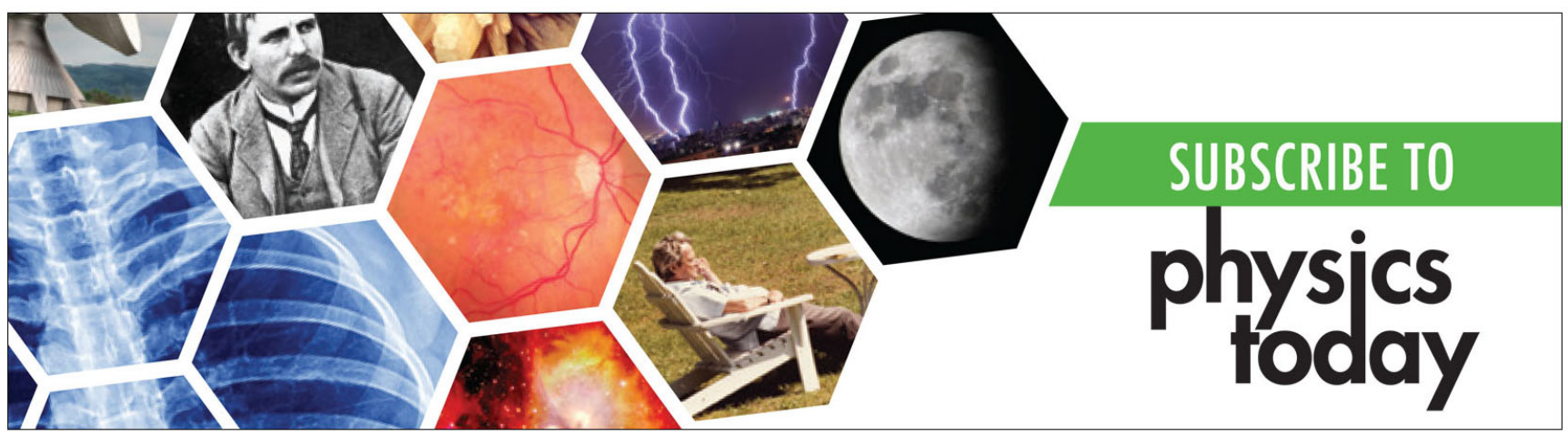




\title{
Universal tight binding model for chemical reactions in solution and at surfaces. III. Stoichiometric and reduced surfaces of titania and the adsorption of water
}

\author{
A. Y. Lozovoi, ${ }^{1}$ D. L. Pashov, ${ }^{2}$ T. J. Sheppard, ${ }^{1}$ J. J. Kohanoff, ${ }^{1}$ and A. T. Paxton ${ }^{2, a)}$ \\ ${ }^{1}$ Atomistic Simulation Centre, School of Mathematics and Physics, Queen's University Belfast, \\ Belfast BT7 1NN, Northern Ireland, United Kingdom \\ ${ }^{2}$ Department of Physics, King's College London, Strand, London WC2R 2LS, United Kingdom
}

(Received 17 April 2014; accepted 25 June 2014; published online 28 July 2014)

\begin{abstract}
We demonstrate a model for stoichiometric and reduced titanium dioxide intended for use in molecular dynamics and other atomistic simulations and based in the polarizable ion tight binding theory. This extends the model introduced in two previous papers from molecular and liquid applications into the solid state, thus completing the task of providing a comprehensive and unified scheme for studying chemical reactions, particularly aimed at problems in catalysis and electrochemistry. As before, experimental results are given priority over theoretical ones in selecting targets for model fitting, for which we used crystal parameters and band gaps of titania bulk polymorphs, rutile and anatase. The model is applied to six low index titania surfaces, with and without oxygen vacancies and adsorbed water molecules, both in dissociated and non-dissociated states. Finally, we present the results of molecular dynamics simulation of an anatase cluster with a number of adsorbed water molecules and discuss the role of edge and corner atoms of the cluster. () 2014 AIP Publishing LLC. [http://dx.doi.org/10.1063/1.4890492]
\end{abstract}

\section{INTRODUCTION}

This is the last of a series of three papers presenting a universal tight binding (TB) model for the electronic structure and interatomic forces in condensed phases. The first two papers, to which we refer below as Paper $\mathrm{I}^{1}$ and Paper II, ${ }^{2}$ describe the application of the model to organic molecules and to polar solvents such as water. In the present paper, we extend our model to a transition metal oxide, in particular $\mathrm{TiO}_{2}$ and analyze its bulk and surface properties, as well as its interaction with water.

Titanium oxide $\mathrm{TiO}_{2}$ (titania) is perhaps one of the most commonly cited materials in the literature. It remains in the center of research interest for many reasons. First of all, $\mathrm{TiO}_{2}$ is a technologically important material. Its applications include dye pigments, surface coatings, electronic devices, surgical implants, and gas sensors. $\mathrm{TiO}_{2}$ is a promising material for photochemical reactions and for heterogeneous catalysis if used together with metal nanoparticles.

Equally important is the role of titania as a model system for studying metal oxides. Crystals of $\mathrm{TiO}_{2}$ have relatively simple structure (rutile, anatase), are easy to prepare, stable, and have only a small amount of bulk or surface defects. Despite this, or maybe because of this, there is still a lot of controversy surrounding titania itself and its interaction with water. An in depth comprehensive review of the current state of research on titania and titania surfaces can be found in Ref. 3, whereas Refs. 4-6 provide an account of most recent progress in understanding the titania-water interaction.

\footnotetext{
a) Author to whom correspondence should be addressed. Electronic mail: Tony.Paxton@KCL.ac.uk.
}

The structure of the paper is as follows. Parameters of the polarizable ion tight binding (PITB) model, extended from the previous work ${ }^{1,2}$ are listed in Sec. II and details of additional fitting procedures are given in Sec. III. Technical details about the calculations to be presented are described in Sec. IV. In Secs. V-IX we present results of simulations using the new model: In Sec. V we describe calculations in bulk, perfect $\mathrm{TiO}_{2}$; Sec. VI contains results of simulations at semi infinite crystal surfaces, both stoichiometric (Sec. VI A) and reduced (Sec. VI B); Sec. VII contains results of simulations of water molecules, both whole and dissociated, absorbed on stoichiometric (Sec. VII A) and reduced (Sec. VII B) $\mathrm{TiO}_{2}$ surfaces. We turn to nanocrystalline anatase particles in Sec. VIII both clean (Sec. VIII A) and decorated with absorbed water molecules (Sec. VIII B). We conclude with Sec. IX.

\section{TIGHT BINDING MODEL OF TITANIA}

As in Papers I and II, ${ }^{1,2}$ we use the self consistent PITB theory described in Refs. 8-11. A concise summary can be found in Paper I. ${ }^{1}$

The set of model parameters sufficient to describe titania and water is presented in Table I. O-O parameters are identical to those in the TB models for water and organic molecules. ${ }^{1,2}$

As seen from Table I, titanium in our orthogonal non spin polarized TB model has only $3 d$ states with $4 s$ states completely neglected. This is possible because Ti- $4 s$ states in $\mathrm{TiO}_{2}$ are shifted into the conduction band by overlap with the oxygen $2 s$ and are hence unoccupied. On the other hand, in terms of polarizability we have to go up to the quadrupole level to 
TABLE I. Parameters of the TB model for titania-water system. See Ref. 1 for the meaning of parameters and abbreviations. O and $\mathrm{H}$ parameters are the same as in Refs. 1 and 2. Notation for the functional form of the scaling law for bond integrals and pair potential is clarified in Table II. All values are given in atomic Rydberg units.

\begin{tabular}{|c|c|c|c|c|c|c|c|}
\hline \multicolumn{8}{|c|}{ On-site parameters } \\
\hline \multicolumn{2}{|c|}{$\mathrm{Ti}$} & & \multicolumn{2}{|c|}{$\mathrm{O}$} & & \multicolumn{2}{|c|}{$\mathrm{H}$} \\
\hline \multirow[t]{2}{*}{$\varepsilon_{d}$} & \multirow[t]{2}{*}{-0.2282} & & \multirow{2}{*}{$\begin{array}{l}\varepsilon_{s} \\
\varepsilon_{p}\end{array}$} & \multirow{2}{*}{\multicolumn{2}{|c|}{$\begin{array}{l}-2.1164 \\
-1.1492\end{array}$}} & \multirow[t]{2}{*}{$\varepsilon_{s}$} & \multirow[t]{2}{*}{-1} \\
\hline & & & & & & & \\
\hline$U$ & 0.9370 & & $\stackrel{p}{U}$ & \multicolumn{2}{|l|}{1.0775} & \multirow[t]{3}{*}{$U$} & \multirow[t]{3}{*}{1} \\
\hline$\Delta_{d d d}$ & 8.0 & & $\Delta_{s p p}$ & \multicolumn{2}{|l|}{-0.9430} & & \\
\hline$\Delta_{d d g}$ & 28.0 & & $\Delta_{p p d}{ }_{p P P}$ & \multicolumn{2}{|l|}{0} & & \\
\hline \multicolumn{8}{|c|}{ Bond integrals, $V_{\ell \ell^{\prime} m}$, and scaling } \\
\hline \multicolumn{2}{|c|}{$\mathrm{Ti}-\mathrm{Ti}$} & \multicolumn{2}{|c|}{$\mathrm{Ti}-\mathrm{O}$} & \multicolumn{2}{|c|}{$\mathrm{O}-\mathrm{H}$} & \multicolumn{2}{|c|}{$\mathrm{O}-\mathrm{O}$} \\
\hline Function & GSP & Function & GSP & Function & GSP & Function & GSP \\
\hline$V_{d d \sigma}^{0}$ & -0.070 & $V_{d s \sigma}^{0}$ & -0.15 & $V_{s s \sigma}^{0}$ & -0.5018 & $V_{s s \sigma}^{0}$ & -0.015 \\
\hline$V_{d d \pi}^{0}$ & 0.055 & $\begin{array}{c}a s \sigma \\
V_{d p \sigma}^{0}\end{array}$ & 0.18 & & & $V_{s p \sigma}^{0}$ & 0.002 \\
\hline \multirow[t]{3}{*}{$V_{d d \delta}^{0}$} & \multirow[t]{3}{*}{0} & $\begin{array}{c}a p \sigma \\
V_{d p \pi}^{0}\end{array}$ & \multirow[t]{3}{*}{-0.12} & $V_{p s \sigma}^{0}$ & -0.4362 & $V_{p s \sigma}^{0}$ & -0.002 \\
\hline & & & & & & $V_{p p \sigma}^{0}$ & 0.050 \\
\hline & & & & & & $V_{p p \pi}^{0}$ & -0.020 \\
\hline$n_{d d \sigma}$ & 5 & $n_{d s \sigma}$ & 4 & $n_{s s \sigma}$ & 2.0963 & $n_{s s \sigma}$ & 2 \\
\hline$n_{d d \pi}$ & 5 & $n_{d p \sigma}$ & 2.1 & & & $n_{s p \sigma}$ & 2 \\
\hline & & $n_{d p \pi}$ & 3.356 & $n_{p s \sigma}$ & 1.5019 & $n_{p s \sigma}$ & 2 \\
\hline & & & & & & $n_{p p \sigma}$ & 3 \\
\hline & & & & & & $n_{p p \pi}$ & 3 \\
\hline$n_{c}$ & 8 & $n_{c}$ & 8 & $n_{c}$ & 4.0561 & $n_{c}$ & 6 \\
\hline$r_{0}$ & 5.55 & $r_{0}$ & 3.685 & $r_{0}$ & 1.8094 & $r_{0}$ & 5.6 \\
\hline$r_{c}$ & 6.93 & $r_{c}$ & 7.37 & $r_{c}$ & 3.7985 & $r_{c}$ & 9.0 \\
\hline & & & Pair pot & , and scalin & & & \\
\hline & & & & & & & \\
\hline Function & EPL & Function & EPL & Function & GSP & Function & EPL \\
\hline$\phi_{1}^{0}$ & 0.015 & $\phi_{1}^{0}$ & $7.340 \times 10^{-3}$ & $\phi^{0}$ & 0.73669 & $\phi_{1}^{0}$ & $4.0306 \times 10^{-3}$ \\
\hline$m_{1}$ & 8 & $m_{1}$ & 12 & $n$ & 3.3502 & $m_{1}$ & 10 \\
\hline$p_{1}$ & 2 & $p_{1}$ & 0 & $n_{c}$ & 6.3096 & $p_{1}$ & 0 \\
\hline & & $\phi_{2}^{0}$ & 0.2212 & $r_{c}$ & 3.3550 & $\phi_{2}^{0}$ & $-2.0265 \times 10^{-3}$ \\
\hline & & $m_{2}$ & 1 & & & $m_{2}$ & 6 \\
\hline & & $p_{2}$ & 1.5933 & & & $p_{2}$ & 0 \\
\hline$r_{0}$ & 5.6 & $r_{0}$ & 3.685 & $r_{0}$ & 1.8094 & $r_{0}$ & 5.6 \\
\hline & & & Cut-off & $\mathrm{s}\left[r_{\text {cut }}^{(1)} ; r_{\text {cut }}^{(2)}\right]$ & & & \\
\hline & & & & & & & \\
\hline$r_{\text {cut }}^{(1)}$ & 7.5 & $r_{\text {cut }}^{(1)}$ & 4 & $r_{\text {cut }}^{(1)}$ & 2.1 & $r_{\text {cut }}^{(1)}$ & 8 \\
\hline$r_{\text {cut }}^{(2)}$ & 10.5 & $r_{\mathrm{cut}}^{(2)}$ & 6 & $r_{\mathrm{cut}}^{(2)}$ & 5.5 & $r_{\mathrm{cut}}^{(2)}$ & 11 \\
\hline
\end{tabular}

describe the crystal field splitting of Ti-3d states into $e_{g}\left(d_{z^{2}}\right.$ and $d_{x^{2}-y^{2}}$ orbitals) and $t_{2 g}$ manifolds $\left(d_{x y}, d_{x z}\right.$, and $d_{y z}$ orbitals). This splitting is a well known feature of transition metal oxides and arises due to the octahedral coordination of Ti atoms. ${ }^{3,12}$ Thus, our titania TB model is a quadrupole model with respect to titanium, and a dipole model with respect to oxygen.

For the scaling law of $\mathrm{Ti}-\mathrm{Ti}$ and $\mathrm{Ti}-\mathrm{O}$ bond integrals we use the Goodwin-Skinner-Pettifor (GSP) $)^{1,7}$ dependence, whereas the Ti-Ti and $\mathrm{Ti}-\mathrm{O}$ pair potentials are described as a sum of exponentials times power law (EPL) functions. Both functional dependencies, GSP and EPL, are explicitly specified in Table II.

The distance dependence of bond integrals and pair potentials is smoothly turned to zero between cutoff radii $r_{\text {cut }}^{(1)}$ and $r_{\text {cut }}^{(2)}$ using multiplicative fifth order polynomials. ${ }^{2}$ This is necessary in order to ensure that no energy leakage or other sources of instability appear in long molecular dynamics (MD) runs. We chose to truncate Ti-O interactions between first and second neighbors in the $\mathrm{TiO}_{2}$ bulk phases, resulting in relatively short Ti-O cutoff radii. Restricting interactions in solids to nearest neighbors usually leads to more reliable and physically motivated models. ${ }^{13} \mathrm{Ti}-\mathrm{Ti}$ interactions, on the other hand, are more extended since there are first neighbor $\mathrm{Ti}-\mathrm{Ti}$ pairs only in the rutile phase of $\mathrm{TiO}_{2}$.

Titania parameters in Table I are expected to be valid not only for simulations of pure titania, but also for titaniawater systems. That was the primary reason for keeping the same oxygen species in water and $\mathrm{TiO}_{2}$. To make the model 
TABLE II. Explicit form of the scaling laws referred to in Table I. Prefactor $A$ denotes $V_{\ell \ell^{\prime} m}^{0}$ in case of bond integrals and $\phi^{0}$ in case of pair potentials.

\begin{tabular}{lll}
\hline \hline Notation & \multicolumn{1}{c}{ Function } & \multicolumn{1}{c}{ Explicit form } \\
\hline GSP & Goodwin-Skinner-Pettifor & $f(r)=A\left(r_{0} / r\right)^{n} \exp \left\{n\left[-\left(r / r_{c}\right)^{n} c+\left(r_{0} / r_{c}\right)^{n} c\right]\right\}$ \\
EPL & Exponential $\times$ Power law & $f(r)=\sum_{i} A_{i}\left(r_{0} / r\right)^{m_{i}} \exp \left[-p_{i}\left(r-r_{0}\right)\right]$ \\
\hline \hline
\end{tabular}

suitable for titania-water simulations, one needs to supply the missing Ti-H interactions. However, since Ti and $\mathrm{H}$, both being positively charged ions, are not expected to approach each other, we simply neglect these interactions. Thus, Ti$\mathrm{H}$ bond integrals are all set to zero, whereas the Ti-H pair potential is weakly repulsive to prevent accidental collisions between Ti and $\mathrm{H}$ species. A similar idea is used in Paper $\mathrm{II}^{2}$ to specify the $\mathrm{H}-\mathrm{H}$ interactions.

\section{FITTING}

The main challenge in the development of the titania model has been the requirement that oxygen in $\mathrm{TiO}_{2}$, water, and organic molecules should be the same species. This is indeed a challenge since $2 s$ electrons of oxygen are of primary importance in water (in particular, their hybridization with O$2 p$ states defines the $\widehat{\mathrm{HOH}}$ angle in the water monomer ${ }^{14}$ ), whereas their role in titania is more modest. The $\mathrm{TiO}_{2}$ valence band (in both rutile and anatase phases) is defined by the O- $2 p$ states, from which O- $2 s$ bands are separated with a wide energy gap (see Fig. 1).

As a consequence of this, titanium oxide tight binding models often ignore $\mathrm{O}-2 s$ states altogether ${ }^{13}$ or replace them with $\mathrm{O}-3 s$ states. $^{15}$ The latter was the case in the TB model developed by Johnston, Benedek, and Paxton ${ }^{16}$ in the course of their work on $\mathrm{SrTiO}_{3}$ from which our $\mathrm{TiO}_{2}$ fitting began.

Fitting of the model parameters started with $\mathrm{O}-\mathrm{O}$ bond integrals. If these were not good enough then nothing could be corrected with other interactions such as $\mathrm{Ti}-\mathrm{O}$ or Ti-Ti. At this step the nearest neighbor bond integrals were fitted to the (a)

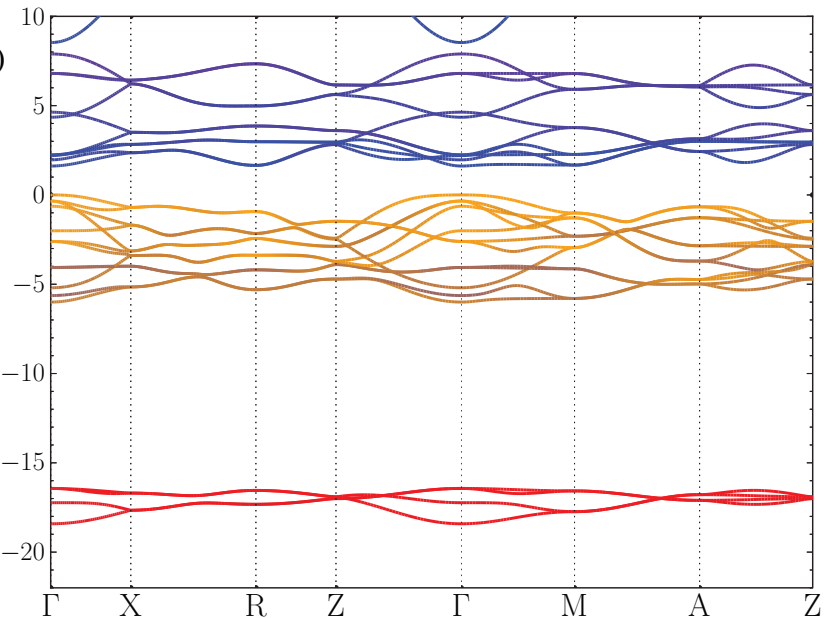

(c)

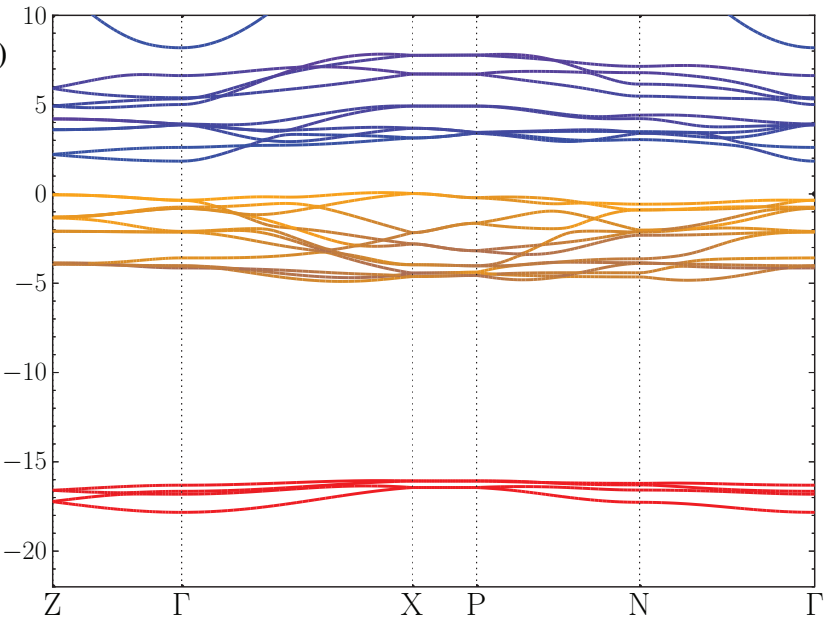

(b)

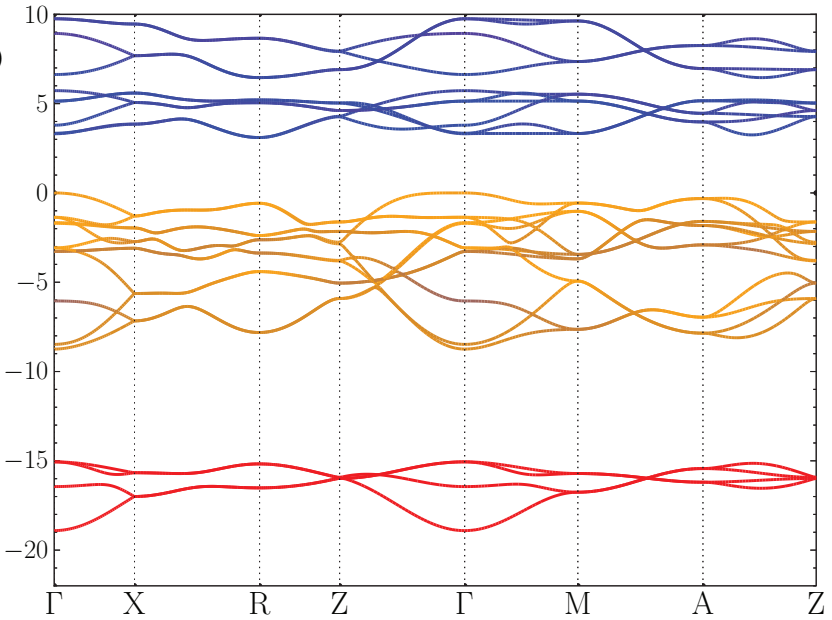

(d)

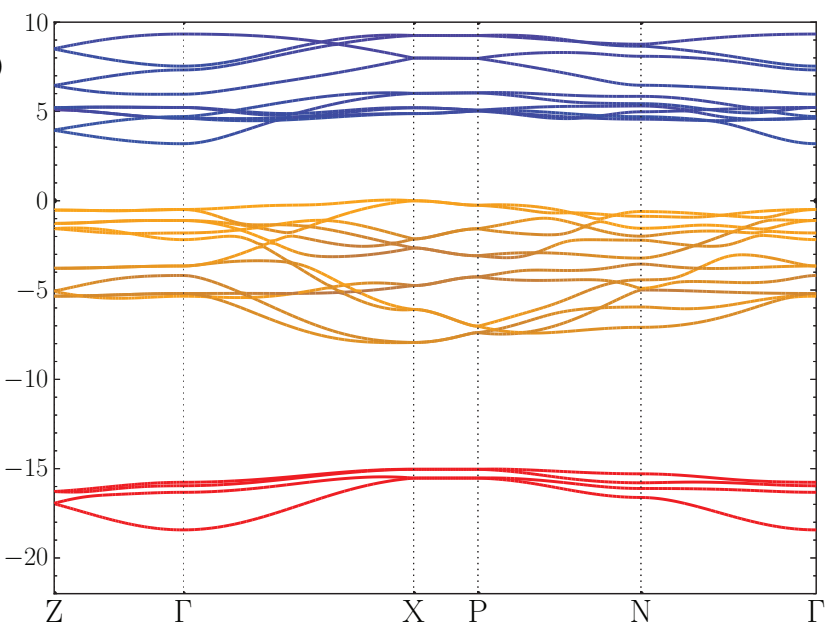

FIG. 1. Energy bands of titania polymorphs obtained at DFT and TB levels: (a) rutile, GGA (PBE); (b) rutile, TB; (c) anatase, GGA (PBE); and (d) anatase, TB. All bands are given at experimental geometry. Oxygen $2 s$ states are shown with red color, oxygen $2 p$ states with orange color, and other states (predominantly Ti-3 $d$ states) with blue color. Note that band gaps in TB calculations were fitted to experiment (see Table III) rather than to DFT results. 
band structure of rutile and anatase at experimental geometry. The distance dependence of bond integrals (scaling laws) was not involved but rather left for subsequent steps.

Note that the above step preceded the fitting of water. ${ }^{2}$ In this regard, the enumeration of papers that constitute the present three paper series is not exactly chronological: the initial O-O bond integrals were found in the present study (Paper III) and then passed to the part dealing with water (Paper II). ${ }^{2}$ In the latter, all $\mathrm{O}-\mathrm{O}$ parameters were finally established and passed to the part dealing with organic molecules (Paper I) ${ }^{1}$ in which they were treated as fixed parameters.

In practical terms, to avoid $\mathrm{O}-\mathrm{O}$ bond integrals being "damaged" at the stage of fitting the water, we estimated acceptable bounds within which the integrals can vary without causing any significant deterioration of $\mathrm{TiO}_{2}$ bands. These bounds were then passed into the water fitting procedure as constraints.

As soon as the water part was finished, the whole set of $\mathrm{O}-\mathrm{O}$ parameters was fixed and fitting of the rest of the titania TB model was resumed. As target quantities we used only bulk properties of rutile and anatase, namely, equilibrium volume, cla ratio, bulk moduli, internal structural parameter, $u$, and the band gaps. These were all taken from experiment. The above properties were complemented with the equilibrium volume of fluorite and rutile-fluorite structural energy difference. Fluorite is a hypothetical phase in $\mathrm{TiO}_{2}$ hence density functional theory (DFT) results were used as targets. They were assigned low weights in the objective function since the only purpose of the inclusion of fluorite was to ensure that it is much higher in energy than rutile and anatase. It is worthwhile recollecting that zirconia, on the other hand, adopts the fluorite structure, the rutile phase being much higher in energy; in fact the present PITB theory was first developed to provide insight into the structure of zirconia and the nature of its phase transitions. ${ }^{8,9,15,17}$

The minimization of the resulting objective function was conducted using Schwefel's genetic algorithm. ${ }^{18,19}$ As both rutile and anatase phases are tetragonal, the full geometry optimization must include finding equilibrium volume $V$ and $c / a$ ratio. The straightforward search with randomly varying parameters supplied by the genetic algorithm turned out to be unstable and therefore inefficient. To circumvent the problem, in the genetic optimization we estimated the equilibrium volume and $c / a$ ratio from single cross sections: $V$ was obtained from the energy-volume curve at experimental $c / a$, and similarly, $c / a$ was obtained at experimental volume.

After the genetic search was finished, we returned to proper geometry optimization in which both $V$ and $c / a$ were minimized simultaneously. That allowed us further to improve equilibrium lattice parameters, as well as the band gaps. This "fine tuning" step was performed manually as the procedure was too unstable for an automatic fitting.

\section{CALCULATION DETAILS}

Tight binding calculations presented in Secs. V-VIII were all done self consistently within the PITB theory as implemented in the TBE program. ${ }^{11,27}$ All TB models used in this study are orthogonal and do not include spin polariza- tion. Geometry optimization was continued until HellmannFeynman forces became smaller than $10^{-4}$ Ry/Bohr and atomic displacements were less than $10^{-4}$ Bohr. Special kpoint Monkhorst-Pack meshes ${ }^{28}$ with density equivalent to the $4 \times 4 \times 4$ mesh in rutile or finer were employed for Brillouin zone sampling, whereas only the $\Gamma$ point was used in MD simulations.

In MD simulations we employ reversible integrators with Liouville operators ${ }^{29}$ and use a single Nosé-Hoover thermostat with relaxation time of $0.1 \mathrm{ps}$, exactly as in Papers I and II. ${ }^{1,2}$ Only canonical (NVT) simulations were made in this study. Unless mentioned otherwise, MD simulations included 20-30 ps of equilibration run followed by at least $100 \mathrm{ps}$ of production run with a time step of $0.5 \mathrm{fs}$.

In addition to TB studies, a few DFT calculations, using both local density approximation (LDA) and generalized gradient approximation (GGA) were done for bulk titania phases (for instance, GGA bands of rutile and anatase in Fig. 1 and LDA rutile-fluorite energy difference in Table III). For these calculations we employed the full potential LMTO program LMF which belongs to the same program suite ${ }^{27}$ as the TBE program.

\section{TITANIA BULK PHASES}

Most common bulk phases of titania are rutile, anatase, and rarely, brookite. We used experimental crystal structure, bulk moduli, and band gaps of rutile and anatase to fit parameters of the TB model. Table III shows how successful we are with the fitting. As discussed in Sec. III, we also included some properties of the fluorite phase (with low weight) to ensure that fluorite is much higher in energy than rutile and anatase.

Two comments on the selection of the target values seem appropriate here. The question as to which of the two phases, rutile or anatase, is lower in energy is still a matter of debate. This is because both phases are rather stable and the energy difference is small. Experimentally rutile is considered to be the lowest energy polymorph of $\mathrm{TiO}_{2}$, whereas convergent DFT GGA calculations favor anatase over rutile, and DFT LDA can predict either result. ${ }^{30,31}$ For the fitting, we required the rutile-anatase energy difference to be as small as possible (i.e., the target was set to 0 ). As a result we arrived at a small negative number meaning that in our model rutile is the lowest energy structure, in apparent agreement with experiment and disagreement with DFT GGA. In Table III we include the most recent experimental result for the enthalpy of the anatase-rutile transformation that we are aware of: $\Delta H_{298}$ $=-1.29 \mathrm{mRy} / \mathrm{f} . \mathrm{u} .(-1.70 \mathrm{~kJ} / \mathrm{mol}){ }^{26}$

A major benefit of TB compared to DFT is that the problem of band gaps can be fixed by fitting them directly to experiment. The target band gaps shown in Table III, $3.03 \mathrm{eV}$ for rutile ${ }^{24}$ and $3.20 \mathrm{eV}$ for anatase ${ }^{25}$ are the results of seminal experiments that are frequently cited and correspond to optical band gaps. There is an ongoing discussion in the literature as to whether the fundamental band gaps would be more appropriate as targets since they do not include electron-hole interaction. ${ }^{32,33}$ However, the current scatter of reported data is too big to make them useful as fitting targets: photoemission 
TABLE III. Equilibrium crystal structure, bulk moduli, and band gaps of $\mathrm{TiO}_{2}$ bulk phases: rutile, anatase, and fluorite. Experimental data cited were used as target values for fitting TB parameters. The exception is fluorite which is a hypothetical phase of titania, hence we used DFT results as targets instead.

\begin{tabular}{|c|c|c|c|c|c|c|}
\hline & \multicolumn{2}{|c|}{ Rutile } & \multicolumn{2}{|c|}{ Anatase } & \multicolumn{2}{|c|}{ Fluorite } \\
\hline & TB & Expt & TB & Expt & $\mathrm{TB}$ & DFT \\
\hline \multicolumn{7}{|c|}{ Lattice constants } \\
\hline$a(\AA)$ & 4.584 & $4.587^{\mathrm{a}}$ & 3.771 & $3.782^{\mathrm{a}}$ & $4.881^{\mathrm{b}}$ & $4.86^{\circ}$ \\
\hline$c(\AA)$ & 2.951 & $2.954^{\mathrm{a}}$ & 9.566 & $9.502^{\mathrm{a}}$ & & \\
\hline$V / V_{\text {target }}$ & 0.9998 & 1 & 1.0006 & 1 & $1.0864^{\mathrm{b}}$ & 1 \\
\hline Internal parameter $u / a$ & 0.303 & $0.305^{\mathrm{a}}$ & 0.212 & $0.208^{\mathrm{a}}$ & & \\
\hline Bulk modulus (GPa) & 282.1 & $211 \pm 7^{\mathrm{d}}$ & 222.3 & $179 \pm 2^{\mathrm{e}}$ & $330.2^{\mathrm{f}}$ & $282^{\mathrm{c}}$ \\
\hline Band gap $(e V)$ & 3.03 & $3.03^{\mathrm{g}}$ & 3.35 & $3.20^{\mathrm{h}}$ & & \\
\hline \multicolumn{7}{|c|}{ Energy differences (mRy per f.u.) } \\
\hline $\mathrm{E}$ (rutile) - E(anatase) & -11.1 & $-1.29^{\mathrm{i}}$ & & & & \\
\hline $\mathrm{E}($ fluorite $)-\mathrm{E}(\text { rutile })^{\mathrm{b}}$ & 67.4 & $51.0^{\mathrm{j}}$ & & & & \\
\hline
\end{tabular}

${ }^{a}$ Neutron diffraction, Ref. 20.

${ }^{\mathrm{b}}$ Used in fitting with low weight.

${ }^{c}$ DFT LDA, Ref. 21.

${ }^{\mathrm{d} X}$ ray diffraction, Ref. 22

${ }^{\mathrm{e}}$ Reference 23 .

${ }^{\mathrm{f}}$ Not included into fitting.

geference 24.

${ }^{\mathrm{h}}$ Reference 25 .

${ }^{\mathrm{i}} \Delta H_{298}$, heat capacity measurements, Ref. 26 . The actual target was set to zero.

${ }^{\mathrm{j} D F T}$ LDA, present study.

spectroscopy gives the electronic band gap in rutile ranging from 3.3 to $4.0 \mathrm{eV}$, which is also the range for hybrid DFT and $G W$ predictions, whereas the situation with anatase is even worse (see, e.g., Ref. 32 and references therein). Hence, we opt to stay with the optical gaps mentioned above. This should be perfectly fine for our study dealing with only ground state simulations, as long as the band gap is wide enough to keep surface defect states confined well inside the gap.

Fig. 1 presents rutile and anatase electronic band structures obtained in DFT and our TB model. The agreement between two sets of bands is rather good, except that the underestimated DFT band gap is corrected in TB. Oxygen $2 s$ states are well separated from oxygen $2 p$ states which mostly constitute the valence band. The position and dispersion of states in the conduction band derived from Ti- $3 d$ electrons is also well reproduced. This is impossible to achieve within a point charge TB model. ${ }^{34}$ It is the titanium crystal field strength parameters $\Delta_{d d d}$ and $\Delta_{d d g}$ (mostly the latter) that provide the required splitting of $e_{g}$ and $t_{2 g} d$-states by the crystal field. The fact that the direct band gap in rutile at the $\Gamma$ point is nearly degenerate with the $\Gamma \rightarrow R$ indirect transition (Fig. 1(a)) is reproduced in our TB model (Fig. 1(b)) except that the $\Gamma \rightarrow$ $R$ transition is slightly smaller than $\Gamma \rightarrow \Gamma$ (by $0.3 \mathrm{eV}$ ). In anatase, however, the indirect gap due to the transition from a $\mathbf{k}$-point along the $\Gamma \rightarrow X$ direction to the $\Gamma$ point (Fig. 1(c)) is rendered correctly in TB (Fig. 1(d)).

\section{TITANIA SURFACES}

\section{A. Ideal surfaces}

Equilibrium surfaces of $\mathrm{TiO}_{2}$ are studied in detail both experimentally and theoretically. The rutile (110) surface in particular is perhaps the model surface of a transition metal oxide. There is a long discussion in the literature ${ }^{41}$ of the apparent disagreement between theory and experiment in the relaxation pattern of surface atoms at rutile (110), similar to that at the $\alpha$-alumina (0001) surface (see Ref. 43 and references therein) and possible reasons for the discrepancy have been suggested. ${ }^{44}$ More careful measurements ${ }^{6}$ and accurate DFT calculations of thicker $\mathrm{TiO}_{2}$ slabs ${ }^{41}$ have served partly to remove the disagreement.

For our study we selected six surfaces listed in Table IV: Rutile (110) and anatase (101) are the lowest energy surfaces, rutile (001) and anatase (001) represent high energy surfaces, whereas rutile (100) and anatase (100) are medium energy surfaces. Calculations are done with $1 \times 1$ periodic supercells containing up to $18 \mathrm{TiO}_{2}$ trilayers. The amount of vacuum separating periodic images along surface normal was chosen generously since in TB it does not affect the computational cost.

The even-odd oscillations that appear for some surfaces, including rutile (110), ${ }^{35,36,38-41}$ are well reproduced in our calculations. This is seen in Fig. 2 where surface energy $E_{\text {surf }}$ is plotted as a function of number of $\mathrm{TiO}_{2}$ trilayers in the slab. The oscillations appear only after atomic relaxation takes place, and the reason for it is related to the tendency of neighboring trilayers to combine into couples thus lowering the total energy of the slab. ${ }^{39}$ Slabs with an odd number of layers then appear at disadvantage compared to even layer slabs.

Due to the oscillations $E_{\text {surf }}$ does not always converge even for the thickest slabs. Because of that, we list in Table IV surface energies corresponding to the two last points in Fig. 2 if the difference exceeds $0.01 \mathrm{~J} / \mathrm{m}^{2}$. Even within the remaining uncertainties, the $\mathrm{TB}$ surface energies are seen to fall comfortably between DFT LDA and GGA energies in 

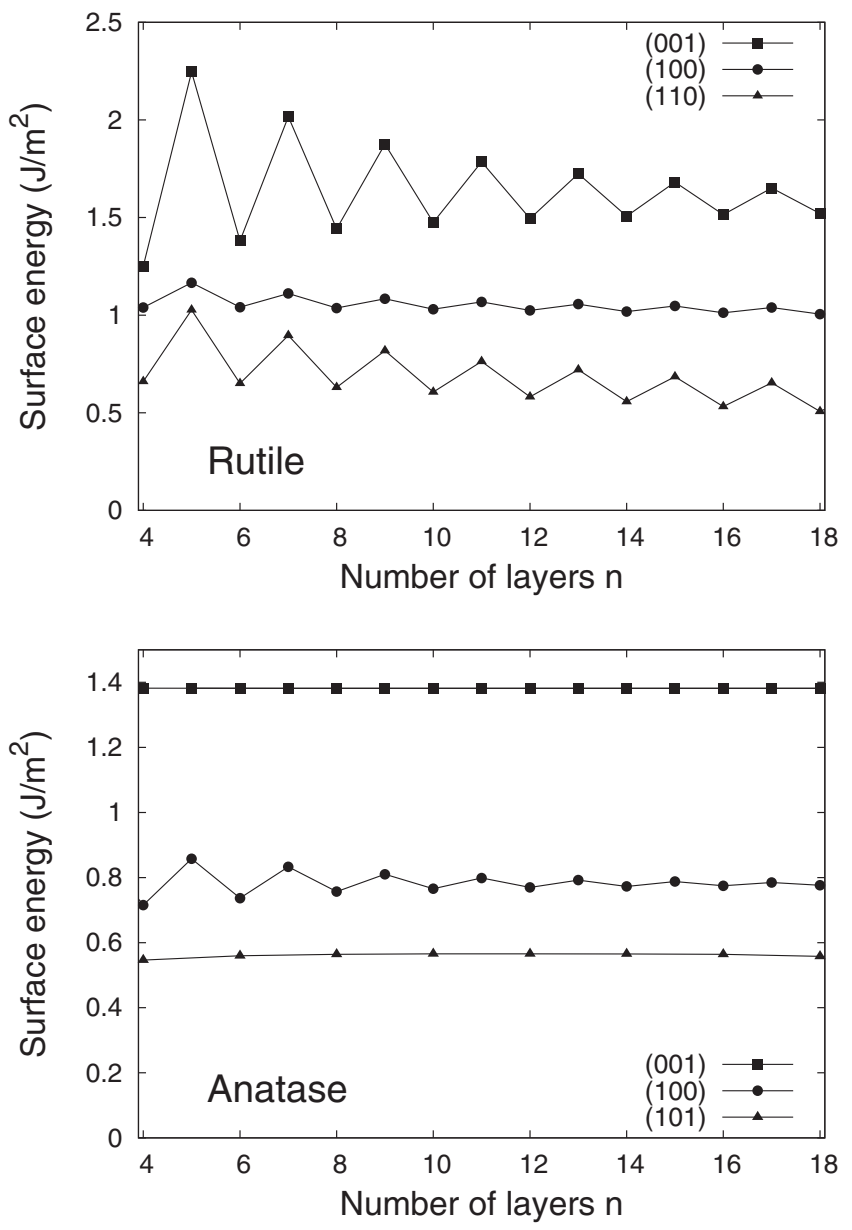

FIG. 2. Surface energy of low index surfaces of rutile (upper panel) and anatase (lower panel) as a function of slab thickness ( $n$ is the number of $\mathrm{TiO}_{2}$ tri-layers in the slab).

Table IV. It is often assumed that LDA (GGA) tends to overestimate (underestimate) surface energies ${ }^{45}$ so we are quite happy with this result especially given that none of the surface properties were included into the fitting (see Sec. III). As a matter of fact, the TB results match most closely those obtained with hybrid functionals. ${ }^{35,40,41}$ In this respect, the agreement for the anatase surfaces is especially impressive. But even apart from matching particular numbers, the most important result is that the relative ordering of surface energies, namely, $E_{\text {surf }}(110)<E_{\text {surf }}(100)<E_{\text {surf }}(001)$ for rutile, and $E_{\text {surf }}(101)<E_{\text {surf }}(100)<E_{\text {surf }}(001)$ for anatase, is perfectly reproduced. That indicates that the main physics governing the cutting and resulting re-hybridization of atomic bonds in the surface region is captured in our model.

\section{B. Reduced surfaces}

Reduced titania surfaces, and in particular surfaces containing oxygen vacancies, $\mathrm{V}_{\mathrm{O}}$, have a significant role to play in numerous applications of $\mathrm{TiO}_{2}$. For example, a rutile (110) unreconstructed surface annealed in UHV may contain as much as $7 \%$ of $\mathrm{V}_{\mathrm{O}}$ residing in the surface rows of so-called bridging (doubly coordinated) oxygen atoms $\mathrm{O}_{2 c} \cdot{ }^{3}$ Surface vacancies are usually the most reactive sites at planar surfaces, hence their significance.
When oxygen atoms are removed from surface as neutral entities, the released electrons occupy states centered at nearby $\mathrm{Ti}$ atoms. ${ }^{61}$ In a band structure picture these states fall inside the band gap and therefore are localized. Since DFT underestimates band gaps, these states can appear too close to the bottom of the conduction band, or even above it, thus becoming more delocalized than they should be. A remedy in such cases is to use $\mathrm{LDA}+U$ or hybrid DFT approaches.

It would therefore be a significant advantage if our TB model could handle oxygen vacancies, which is a possibility given that the bulk band gaps in both rutile and anatase are aligned with experimental ones at the fitting stage (see Sec. V). However, none of the properties related to point defects was included into the fitting; hence any encouraging results obtained for $\mathrm{V}_{\mathrm{O}}$ would be exclusively due to the transferability of the self consistent PITB theory.

Table $\mathrm{V}$ lists the formation energies of an oxygen vacancy, $E^{f}\left(\mathrm{~V}_{\mathrm{O}}\right)$, at all six titania surfaces studied in Sec. VI A. These energies are obtained by creating a single vacancy at a $3 \times 3$ cell for anatase (001) and rutile (001) and $2 \times 4$ slabs for the other surfaces, which translates into vacancy coverage of $1 / 9 \mathrm{ML}$ and $1 / 8 \mathrm{ML}$, respectively. The (001) slabs contain $8 \mathrm{TiO}_{2}$ trilayers, rutile (110) comprises $5 \mathrm{TiO}_{2}$ trilayers, and the rest of the slabs contain $6 \mathrm{TiO}_{2}$ trilayers. Altogether, the periodic supercells include 144 atomic sites for rutile (100), 216 sites for both (001) cells, 240 sites for rutile (110), and 288 sites for anatase (101) slabs. Vacancies are placed on both sides except anatase (101) for which we use one-sided geometry.

Instead of absolute formation energies, we give in Table $\mathrm{V}$ energies relative to $E^{f}\left(\mathrm{~V}_{\mathrm{O}}\right)$ at the rutile (110) surface since we do not have a reliable energy of the $\mathrm{O}_{2}$ molecule in our non spin polarized TB model. ${ }^{62}$ Thus, the direct comparison between TB and various DFT energies in Table V is not accessible. However, we can use results of Cheng and Selloni ${ }^{46}$ to estimate the difference $E^{f}\left(\mathrm{~V}_{\mathrm{O}}\right)$ [anatase (101)] $-E^{f}\left(\mathrm{~V}_{\mathrm{O}}\right)$ [rutile (110)] for which DFT GGA (PBE) gives $0.57 \mathrm{eV}$ whereas within the $\mathrm{PBE}+U$ approach this difference varies between $0.78 \mathrm{eV}$ at $U=3.0 \mathrm{eV}$ and $0.51 \mathrm{eV}$ at $U=4.5 \mathrm{eV}$. The TB result is $1.54 \mathrm{eV}$ and is a factor of 2-3 larger. Note, however, that because of the use of different supercells for rutile (110) and anatase (101) in DFT, the comparison we make above is approximate.

A more precise comparison between TB and DFT can be made for energy differences corresponding to exchanges of $\mathrm{V}_{\mathrm{O}}$ between titania layers as well as for the complex $\mathrm{TiO}_{2}$ vacancy. For the latter we again find that our TB model overestimates $E^{f}\left(\mathrm{~V}_{\mathrm{TiO}_{2}}\right)$ by a factor of two. Similar overestimation is found for the vacancy jump in rutile (110). The agreement between TB and DFT is only semi quantitative, yet we find it encouraging that in the absence of any specific effort the model already provides meaningful results. We expect that the model can be further improved to capture events at reduced titania surfaces better. It is conceivable for instance that the overestimation of vacancy formation energies is due to the omission of spin polarization effects in our model, as it leads to the reduction of degrees of freedom for the electronic subsystem. 
TABLE IV. Energy of low index surfaces of rutile and anatase (in $\mathrm{J} / \mathrm{m}^{2}$ ): TB prediction in comparison with LDA, GGA, and hybrid DFT results. Due to oscillatory convergence of surface energy with slab thickness (see Fig. 2) TB surface energies are given for both 17- and 18-trilayer slabs if the difference between them exceeds $0.01 \mathrm{~J} / \mathrm{m}^{2}$.

\begin{tabular}{|c|c|c|c|c|c|c|}
\hline \multirow[b]{3}{*}{ Surface } & \multirow[b]{3}{*}{$\mathrm{TB}$} & \multicolumn{5}{|c|}{ DFT } \\
\hline & & \multirow[b]{2}{*}{ LDA } & \multirow{2}{*}{$\begin{array}{l}\text { GGA } \\
\text { PBE }\end{array}$} & \multicolumn{3}{|c|}{ Hybrid } \\
\hline & & & & B3LYP & PBE0 & PW1PW \\
\hline & & & Rutile & & & \\
\hline \multirow[t]{2}{*}{ (110) } & $0.51-0.65$ & $0.89^{\mathrm{a}}$ & $0.42,{ }^{\mathrm{a}} 0.31^{\mathrm{b}}$ & $0.40^{\mathrm{a}}$ & $0.55^{\mathrm{a}}$ & $0.62^{\mathrm{c}}$ \\
\hline & & & $0.47,^{\mathrm{d}} 0.36^{\mathrm{e}}$ & & $0.57^{\mathrm{f}}$ & \\
\hline \multirow[t]{2}{*}{ (100) } & $1.01-1.04$ & $1.20^{\mathrm{a}}$ & $0.69^{\mathrm{a}}$ & $0.70^{\mathrm{a}}$ & $0.83^{\mathrm{a}}$ & $0.85^{\mathrm{c}}$ \\
\hline & & & & & $0.85^{\mathrm{f}}$ & \\
\hline \multirow[t]{2}{*}{$(001)$} & $1.52-1.65$ & $1.88^{\mathrm{a}}$ & $1.39^{\mathrm{a}}$ & $1.45^{\mathrm{a}}$ & $1.59^{\mathrm{a}}$ & $1.47^{\mathrm{c}}$ \\
\hline & & & & & $1.55^{\mathrm{f}}$ & \\
\hline & & & Anatase & & & \\
\hline (101) & 0.56 & $0.83^{\mathrm{a}}$ & $0.50,{ }^{\mathrm{a}} 0.44^{\mathrm{b}}$ & $0.55^{\mathrm{a}}$ & $0.60^{\mathrm{a}}$ & $0.64^{\mathrm{c}}$ \\
\hline (100) & 0.78 & $0.97^{\mathrm{a}}$ & $0.63,{ }^{\mathrm{a}} 0.53^{\mathrm{b}}$ & $0.67^{\mathrm{a}}$ & $0.73^{\mathrm{a}}$ & $0.81^{\mathrm{c}}$ \\
\hline (001) & 1.38 & & $0.98,^{\mathrm{g}} 0.90^{\mathrm{b}}$ & & & $1.36^{\mathrm{c}}$ \\
\hline \multicolumn{7}{|c|}{${ }^{\mathrm{a}}$ Reference 35.} \\
\hline \multicolumn{7}{|c|}{${ }^{\mathrm{b}}$ References 36 and 37.} \\
\hline \multicolumn{7}{|c|}{${ }^{\mathrm{c}}$ Reference 41.} \\
\hline \multicolumn{7}{|c|}{${ }^{\mathrm{d}}$ Reference 38.} \\
\hline \multicolumn{7}{|c|}{${ }^{\mathrm{e}}$ Reference 39} \\
\hline \multicolumn{7}{|c|}{${ }^{\mathrm{f}}$ Reference 40 , data taken from graph. } \\
\hline
\end{tabular}

TABLE V. Formation energies $E^{f}$ (in eV) of oxygen vacancies and related defects at pure titania surfaces. TB formation energies of isolated oxygen vacancies are given relative to that at the rutile (110) surface. DFT vacancy formation energies are the absolute energies obtained in the oxygen-rich limit.

\begin{tabular}{|c|c|c|c|c|c|}
\hline Surface & $\begin{array}{c}\text { Site } \\
\text { (jump type) }\end{array}$ & TB & DFT & $\begin{array}{l}\text { DFT } \\
+U\end{array}$ & $\begin{array}{c}\text { Hybrid } \\
\text { DFT }\end{array}$ \\
\hline \multicolumn{6}{|c|}{ Surface oxygen vacancy (layer 1) } \\
\hline \multirow[t]{3}{*}{ Rutile(110) } & $\mathrm{O}_{2 c}$ & $0^{\mathrm{a}}$ & $3.68^{\mathrm{b}}$ & $2.88^{\mathrm{b}}$ & \\
\hline & & & $3.02^{\mathrm{c}}$ & & \\
\hline & & & $3.85^{\mathrm{d}}$ & & \\
\hline Rutile(100) & $\mathrm{O}_{2 c}$ & $0.22^{\mathrm{a}}$ & & & \\
\hline Rutile(001) & $\mathrm{O}_{2 c}$ & $1.18^{\mathrm{a}}$ & & & \\
\hline Anatase(101) & $\mathrm{O}_{2 c}$ & $1.54^{\mathrm{a}}$ & $4.25^{\mathrm{b}}$ & $3.39^{\mathrm{b}}$ & \\
\hline Anatase(100) & $\mathrm{O}_{2 c}$ & $1.18^{\mathrm{a}}$ & & & \\
\hline Anatase(001) & $\mathrm{O}_{2 c}$ & $0.13^{\mathrm{a}}$ & & & \\
\hline \multicolumn{6}{|c|}{ Oxygen vacancy jumps } \\
\hline Rutile(110) & Layers $1 \rightarrow 2$ & 1.70 & $0.82^{\mathrm{b}}$ & & \\
\hline \multirow{7}{*}{ Anatase(101) } & & & $0.98^{\mathrm{c}}$ & & \\
\hline & & & $1.14^{\mathrm{d}}$ & & \\
\hline & Layers $1 \rightarrow 4$ & & $1.55^{\mathrm{b}}$ & $0.51^{\mathrm{b}}$ & \\
\hline & Layers $1 \rightarrow 2$ & 0.21 & $1.15^{\mathrm{b}}$ & & \\
\hline & Layers $2 \rightarrow 3$ & 0.17 & $-0.67^{b}$ & & \\
\hline & Layers $3 \rightarrow 4$ & 0.01 & $-0.70^{\mathrm{b}}$ & & \\
\hline & Layers $1 \rightarrow 4$ & 0.38 & $-0.22^{b}$ & $0.33^{\mathrm{b}}$ & $-0.61^{\mathrm{e}}$ \\
\hline \multicolumn{6}{|c|}{$\mathrm{TiO}_{2}$ vacancy } \\
\hline Rutile(110) & $\mathrm{Ti}_{5 c}+2 \mathrm{O}_{2 c}$ & 2.05 & $1.03^{\mathrm{c}}$ & & \\
\hline
\end{tabular}

${ }^{\mathrm{a}} \mathrm{TB} \mathrm{V}_{\mathrm{O}}$ formation energies are given relatively to that at rutile(110) surface. ${ }^{\mathrm{b}} \mathrm{PBE}$ and $\mathrm{PBE}+U$, Ref. 46 . $\mathrm{PBE}+U$ results are cited for $U=4.5 \mathrm{eV}$.

${ }^{\mathrm{c}}$ PBE, Ref. 39.

dPBE, Ref. 47.

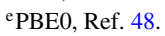

To proceed, we now consider vacancy exchanges at anatase (101) and rutile (110) surfaces. It was discovered by Cheng and Selloni (see Ref. 46 and references therein) that DFT GGA (PBE) predicts subsurface $\mathrm{V}_{\mathrm{O}}$ to be lower in energy than $V_{O}$ at the surface layer as seen in Table $V$ (the layer 4 vacancy site is situated directly below the layer 1 vacancy site). $\mathrm{PBE}+U$ results are not conclusive in this respect: the layer 4 vacancy is more stable than layer 1 vacancy at $U$ $=2.5 \mathrm{eV}$ but at $U=4.5 \mathrm{eV}$ this is reversed. In a more recent study combining STM measurements and hybrid PBE0 calculations, the subsurface vacancy was again found more favorable. ${ }^{48}$ In our TB model the preference of the subsurface site is not reproduced: the TB prediction is that the layer $1 \rightarrow$ layer 4 jump costs $0.38 \mathrm{eV}$, which agrees with the $\mathrm{PBE}+U$ result of $0.33 \mathrm{eV}$ (with $U=4.5 \mathrm{eV}$ ) but disagrees with plain PBE and hybrid PBE0 values of $-0.22 \mathrm{eV}^{46}$ and $-0.61 \mathrm{eV},{ }^{48}$ respectively.

For rutile (110) the first layer vacancy is the lowest energy according to both TB and DFT, although TB again overestimates the energy of the vacancy jump from the bridging oxygen row into the in-plane position in the surface layer by a factor of two. Note in passing that our TB model predicts the following ordering of surface vacancies in energy: rutile (110) $<$ anatase $(001) \simeq$ rutile $(100)<$ rutile $(001) \simeq$ anatase $(100)$ $<$ anatase (101). In fact it is well known that oxygen vacancies at the (110) surface of rutile are easily created by thermal annealing, ${ }^{3}$ whereas oxygen vacancies at anatase (101) have such high energy that they migrate into the bulk of the material during annealing. ${ }^{48}$ 
It is interesting that surface vacancy formation energies do not show any correlation with surface energies. In particular, the vacancies with the highest and lowest energy from the above list are those at rutile (110) and anatase (101), which are both the lowest energy surfaces of rutile and anatase, respectively.

\section{ADSORBED WATER MOLECULES}

One of the reasons for developing our TB model in the way we did, was to make it possible to simulate complex systems with both titania and water present. An isolated water molecule adsorbed on $\mathrm{TiO}_{2}$ surfaces is, perhaps, the simplest type of a water-titania system. Yet it would be impossible to study the adsorption of water into an oxygen vacancy if oxygen of water and oxygen of titania were not the same species. In Sec. VII A, we look first into the water adsorption on ideal $\mathrm{TiO}_{2}$, and then, in Sec. VII B, present our results for the adsorption on reduced titania.

\section{A. Adsorption at ideal surfaces}

Water readily adsorbs on $\mathrm{TiO}_{2}$ as has been known since the seminal discovery of the fact that titania can split adsorbed water into $\mathrm{O}_{2}$ and $\mathrm{H}_{2}$ molecules by means of photolysis. ${ }^{64}$ Nevertheless, the question as to whether a single water molecule dissociates on the (110) surface of rutile still remains under intensive debate. Most experimental studies suggest that water molecules should dissociate on all titania surfaces except perfect unreconstructed rutile (110) and anatase (101). ${ }^{3,5}$ However, some recent experimental studies of ideal rutile (110) terraces report dissociated water molecules which are not related to oxygen vacancies, surface steps, or other types of surface defects. ${ }^{65,66}$ An interesting explanation was proposed by Walle et al. ${ }^{67}$ who suggested that water molecules already dissociated at $\mathrm{V}_{\mathrm{O}}$ could impede the dissociation for other molecules, which is why the dissociated molecules are observed in some studies and not observed in others.

Theoretical computations (mostly DFT) produce results of either type, as the water adsorption energies, both in the associated (molecular) state, $E_{\text {ads }}^{\mathrm{mol}}$, and in the dissociated state, $E_{\text {ads }}^{\text {dis }}$, strongly depend on computational details, such as the coverage, slab width, relaxation constraints, and the exchange-correlation functional employed. This is illustrated in Table VI in which we cite a few (out of many) recent calculations corresponding to coverage $\Theta=1 / 4$ and lower, and to slab thickness of at least four $\mathrm{TiO}_{2}$ trilayers.

Our TB results for rutile (110) favor dissociated water in agreement with Refs. 39 and 54 and in disagreement with Refs. 53, 55, and 56. In its absolute value, $E_{\text {ads }}^{\mathrm{mol}}$ is in excellent agreement with DFT results and experiment, but $E_{\text {ads }}^{\text {dis }}$ seems overestimated. In order to get a better understanding of the water dissociation process, we made a number of $50 \mathrm{ps}$ long MD NVT simulations at temperatures $300 \mathrm{~K}, 400 \mathrm{~K}, 500 \mathrm{~K}$, and $600 \mathrm{~K}$. Since TB predicts $E_{\text {ads }}^{\text {dis }}$ almost twice as negative as $E_{\mathrm{ads}}^{\mathrm{mol}}$, one would expect dissociation to happen straight away. However, only in one simulation did we observe water disso- ciation at $T=500 \mathrm{~K}$. At $300 \mathrm{~K}$ and $400 \mathrm{~K}$ we did not detect any events, at $500 \mathrm{~K}$ water molecules mostly diffused along the surface instead of dissociating, and at $600 \mathrm{~K}$ they moved along rows of bridging oxygens, jumped over them, formed hydrogen bonds with bridging oxygens, and eventually left the surface. It is possible that the observed behavior might be relevant to the reluctance of water to dissociate on the perfect (110) surface of rutile.

For the water adsorption on rutile (100) surface, TB predicts the dissociated and non-dissociated states to be close in energy, with a slight preference for the dissociation. PBE calculations by Kamisaka and Yamashita ${ }^{53}$ favor the nondissociated state by $0.25 \mathrm{eV}$ (see Table VI), whereas experimentally both dissociative and molecular adsorption are observed - the current view is that water initially adsorbs dissociatively, followed by the molecular adsorption at higher coverage. ${ }^{3}$

The rutile (001) surface (see Table IV) has only fourfold coordinated $\mathrm{Ti}_{4 c}$ and twofold coordinated $\mathrm{O}_{2 c}$ exposed. As a result, it is less stable than other surfaces and tends to facet or reconstruct. Hence, it is not a common subject for experimental and theoretical investigation. A few existing studies agree on the dissociative water adsorption. ${ }^{3} \mathrm{~TB}$ also predicts that dissociative adsorption is favored by $0.37 \mathrm{eV}$.

In the anatase part of Table VI we observe a good agreement between TB results and DFT results for all three surfaces: (101), (100), and (001). Dissociation is not favored for anatase (101), but is favored on (100) and (001) surfaces, with a sizable energetic effect in the latter case. This is the only case in which the dissociation occurs straight away in our MD simulations, and it takes only 3-6 ps to happen. A large negative $E_{\mathrm{ads}}^{\mathrm{dis}}$ for the anatase (001) surface is also found in DFT GGA calculations. ${ }^{42,60}$

Overall we conclude that our TB model adequately describes the principal features related to water adsorption and dissociation at ideal stoichiometric titania surfaces.

\section{B. Adsorption at reduced surfaces}

Experiment suggests that the adsorption of a water molecule into an oxygen vacancy at the (110) surface of rutile should lead to straight decomposition of $\mathrm{H}_{2} \mathrm{O}$ into two hydroxyl groups situated next to each other in the bridging oxygen row. ${ }^{5} \mathrm{PBE}^{53,57}$ and $\mathrm{PBE}+U^{57}$ simulations confirm that the dissociated molecule has a large negative adsorption energy, especially within the $\mathrm{PBE}+U$ approach (see the "(110) $+\mathrm{V}_{\mathrm{O}}$ " row in Table VI). The TB prediction is that both $E_{\mathrm{ads}}^{\mathrm{mol}}$ and $E_{\text {ads }}^{\text {dis }}$ are large and negative, with $E_{\text {ads }}^{\text {dis }}$ being lower. That means that the adsorbed $\mathrm{H}_{2} \mathrm{O}$ molecule should dissociate, in apparent agreement with experiment.

A closer inspection of the TB data, however, reveals that it is more favorable for an adsorbed molecule on the reduced surface to move onto a nearest neighbor $(\mathrm{NN}) \mathrm{Ti}_{5 c}$ site and then further down to the next nearest neighbor (NNN) or third nearest neighbor $(3 \mathrm{NN}) \mathrm{Ti}_{5 c}$ site and to dissociate there. In fact, that was exactly the behavior we observed in an MD NVT simulation of $\mathrm{H}_{2} \mathrm{O}$ adsorbed into an oxygen vacancy on rutile (110), at least in the initial stages of the simulation: the 
TABLE VI. Adsorption energies (in eV) of a water molecule in the dissociated $E_{\text {ads }}^{\text {dis }}$ and molecular state $E_{\text {ads }}^{\text {mol }}$, together with the dissociation energy $\Delta E_{\text {diss }}$ $=E_{\text {ads }}^{\text {dis }}-E_{\text {ads }}^{\text {mol }}$. Adsorption sites NN, NNN, and $3 \mathrm{NN}$ refer to the nearest neighbor, next nearest neighbor, and third nearest neighbor Ti site as seen from the oxygen vacancy on reduced titania surfaces. The sign convention is that a negative adsorption/dissociation energy favors adsorption/dissociation. For an extended compilation of recent DFT results see Refs. 4 and 49.

\begin{tabular}{|c|c|c|c|c|c|c|c|c|c|c|c|}
\hline \multirow[b]{2}{*}{ Surface } & \multirow{2}{*}{$\begin{array}{c}\text { Adsorption } \\
\text { site }\end{array}$} & \multicolumn{3}{|c|}{$\mathrm{TB}$} & \multicolumn{3}{|c|}{ DFT (GGA) } & \multicolumn{3}{|c|}{$\mathrm{GGA}+U$} & \multirow[b]{2}{*}{ Experiment } \\
\hline & & $E_{\mathrm{ads}}^{\mathrm{mol}}$ & $E_{\text {ads }}^{\text {diss }}$ & $\Delta E_{\text {diss }}$ & $E_{\mathrm{ads}}^{\mathrm{mol}}$ & $E_{\text {ads }}^{\text {diss }}$ & $\Delta E_{\text {diss }}$ & $E_{\text {ads }}^{\text {mol }}$ & $E_{\text {ads }}^{\text {diss }}$ & $\Delta E_{\text {diss }}$ & \\
\hline & & & & & & Rutile & & & & & \\
\hline \multirow[t]{5}{*}{ (110) } & $\mathrm{Ti}_{5 c}$ & -0.92 & -1.72 & -0.79 & $-0.93^{\mathrm{a}}$ & $-1.04^{\mathrm{a}}$ & $-0.11^{\mathrm{a}}$ & & & & $-0.73,,^{b}-0.72,{ }^{b}-0.79^{b}$ \\
\hline & & & & & $-0.70^{\mathrm{c}}$ & $-0.46^{\mathrm{c}}$ & $0.24^{\mathrm{c}}$ & & & & \\
\hline & & & & & $-0.49^{\mathrm{d}}$ & $-0.68^{\mathrm{d}}$ & $-0.19^{\mathrm{d}}$ & & & & \\
\hline & & & & & $-0.76^{\mathrm{e}}$ & $-0.66^{\mathrm{e}}$ & $0.10^{\mathrm{e}}$ & & & & \\
\hline & & & & & $-0.95^{\mathrm{f}}$ & $-0.90^{\mathrm{f}}$ & $0.05^{\mathrm{f}}$ & & & & \\
\hline \multirow[t]{5}{*}{$(110)+\mathrm{V}_{\mathrm{O}}$} & $\mathrm{O}_{2 c}$ & -1.43 & -2.06 & -0.63 & & $-1.30^{\mathrm{c}}$ & & & & & \\
\hline & & & & & & $-1.18^{\mathrm{g}}$ & & & $-1.61^{\mathrm{g}}$ & & \\
\hline & $\mathrm{NN} \mathrm{Ti}_{5 c}$ & -1.44 & -1.68 & -0.24 & $-0.80^{g}$ & $-0.89^{\mathrm{g}}$ & $-0.09^{g}$ & $-0.77^{g}$ & $-0.87^{\mathrm{g}}$ & $-0.10^{\mathrm{g}}$ & \\
\hline & $\mathrm{NNN} \mathrm{Ti} i_{5 c}$ & -1.57 & -2.18 & -0.61 & $-0.81^{\mathrm{g}}$ & $-0.95^{\mathrm{g}}$ & $-0.14^{\mathrm{g}}$ & $-0.83^{\mathrm{g}}$ & $-0.92^{\mathrm{g}}$ & $-0.09^{\mathrm{g}}$ & \\
\hline & $3 \mathrm{NN} \mathrm{Ti}{ }_{5 c}$ & -1.56 & -1.92 & -0.36 & $-0.82^{\mathrm{g}}$ & $-0.90^{\mathrm{g}}$ & $-0.08^{\mathrm{g}}$ & $-0.84^{\mathrm{g}}$ & $-0.89^{\mathrm{g}}$ & $-0.05^{\mathrm{g}}$ & \\
\hline$(100)$ & $\mathrm{Ti}_{5 c}$ & -1.07 & -1.10 & -0.03 & $-0.91^{\mathrm{c}}$ & $-0.66^{\mathrm{c}}$ & $0.25^{\mathrm{c}}$ & & & & \\
\hline \multirow[t]{3}{*}{$(100)+\mathrm{V}_{\mathrm{O}}$} & $\mathrm{O}_{2 c}$ & 0.31 & -0.52 & -0.83 & & $-1.39^{\mathrm{c}}$ & & & & & \\
\hline & $\mathrm{NN} \mathrm{Ti}_{5 c}$ & -0.43 & -0.37 & 0.06 & & & & & & & \\
\hline & $\mathrm{NNN} \mathrm{Ti}_{5 c}$ & 0.35 & 0.27 & -0.08 & & & & & & & \\
\hline$(001)$ & $\mathrm{Ti}_{4 c}$ & -1.14 & -1.51 & -0.37 & & & & & & & \\
\hline \multirow[t]{3}{*}{$(001)+V_{O}$} & $\mathrm{O}_{2 c}$ & -1.01 & -2.41 & -1.18 & & & & & & & \\
\hline & $\mathrm{NN} \mathrm{Ti}_{4 c}$ & -0.42 & -0.32 & 0.10 & & & & & & & \\
\hline & $\mathrm{NNN} \mathrm{Ti}_{4 c}$ & -0.37 & -0.09 & 0.28 & & & & & & & \\
\hline \multirow{3}{*}{ (101) } & & & & & & Anatase & & & & & \\
\hline & $\mathrm{Ti}_{5 c}$ & -0.81 & -0.52 & 0.29 & $-0.73^{\mathrm{h}}$ & & & & & & $-0.69^{\mathrm{i}}$ \\
\hline & & & & & $-0.95^{\mathrm{j}}$ & $-0.66^{j}$ & $0.29^{\mathrm{j}}$ & & & & \\
\hline \multirow[t]{3}{*}{$(101)+V_{O}$} & $\mathrm{O}_{2 c}$ & -1.22 & -2.45 & -1.23 & & & & & & & \\
\hline & $\mathrm{NN} \mathrm{Ti}_{5 c}$ & -0.75 & -0.55 & 0.20 & & & & & & & \\
\hline & $\mathrm{NNN} \mathrm{Ti}_{5 c}$ & -0.57 & -0.43 & 0.14 & & & & & & & \\
\hline (100) & $\mathrm{Ti}_{5 c}$ & -0.70 & -1.15 & -0.46 & $-0.74^{j}$ & $-0.78^{\mathrm{j}}$ & $-0.03^{j}$ & & & & \\
\hline \multirow[t]{3}{*}{$(100)+V_{O}$} & $\mathrm{O}_{2 c}$ & -1.11 & -2.22 & -1.11 & & & & & & & \\
\hline & $\mathrm{NN} \mathrm{Ti}_{5 c}$ & -1.11 & -2.24 & -1.14 & & & & & & & \\
\hline & $\mathrm{NNN} \mathrm{Ti}_{5 c}$ & -0.51 & -1.25 & -0.74 & & & & & & & \\
\hline \multirow[t]{2}{*}{ (001) } & $\mathrm{Ti}_{5 c}$ & -0.58 & -2.33 & -1.76 & $-1.15^{\mathrm{j}}$ & $-2.84^{j}$ & $-1.68^{\mathrm{j}}$ & & & & \\
\hline & & & & & & $-1.25^{\mathrm{k}}$ & & & & & \\
\hline \multirow[t]{3}{*}{$(001)+V_{O}$} & $\mathrm{O}_{2 c}$ & -1.05 & -3.06 & -2.01 & & & & & & & \\
\hline & $\mathrm{NN} \mathrm{Ti}_{5 c}$ & -0.34 & -2.47 & -2.13 & & & & & & & \\
\hline & NNN $\operatorname{Ti}_{5 c}$ & -0.64 & -2.46 & -0.64 & & & & & & & \\
\hline
\end{tabular}

${ }^{\mathrm{a}}$ Reference 39: $\mathrm{PBE}, \Theta=1 / 8$, 4 layer $\mathrm{TiO}_{2}$ slab, one-sided adsorption with passivation.

${ }^{\mathrm{b}}$ Temperature-programmed desorption: adsorption energies as a function of coverage $(71-9 \Theta) \mathrm{kJ} / \mathrm{mol}[$ Ref. 50$],(70-7 \Theta) \mathrm{kJ} / \mathrm{mol}[\mathrm{Refs} .51$ and 52$]$, and $(80-35 \Theta) \mathrm{kJ} / \mathrm{mol}[$ Ref. 52], respectively, interpolated into $\Theta=1 / 8$ and converted into $\mathrm{eV}$ units.

${ }^{\mathrm{c}}$ Ref. 53: PBE, $\Theta=1 / 3$ for (110) surface and $\Theta=1 / 4$ for (100) surface, 4 layer $\mathrm{TiO}_{2}$ slab, one-sided adsorption.

${ }^{\mathrm{d}}$ Reference 54: RPBE, $\Theta=1 / 4,5$ layer $\mathrm{TiO}$, slab, two-sided adsorption.

${ }^{\text {e}}$ Reference 55: PBE, $\Theta=1 / 4,4$ layer $\mathrm{TiO}_{2}$ slab, one-sided adsorption.

${ }^{\mathrm{f}}$ Reference 56: PW91, $\Theta=1 / 5,5$ layer $\mathrm{TiO}_{2}$ slab, two-sided adsorption.

${ }^{g}$ Reference 57: $\mathrm{PBE}$ and $\mathrm{PBE}+U$ with $U=4.2 \mathrm{eV}, \Theta=1 / 8,4$ layer $\mathrm{TiO}_{2}$ slab, one-sided adsorption with passivation.

${ }^{\mathrm{h}}$ Reference 58: PBE, $\Theta=1 / 4,4$ layer $\mathrm{TiO}_{2}$ slab.

${ }^{\mathrm{i}}$ Reference 59: Temperature-programmed desorption.

${ }^{\mathrm{j}}$ Reference 60: PBE, $\Theta=1 / 9-1 / 4$ depending on surface, 8 layer $\mathrm{TiO}_{2}$ slab with 4 bottom layers fixed, one-sided adsorption.

${ }^{\mathrm{k}}$ Reference 42: $\mathrm{PBE}, \Theta=1 / 6$, 4 layer $\mathrm{TiO}_{2}$ slab, one-sided adsorption.

molecule eventually vacates the $\mathrm{V}_{\mathrm{O}}$ site and moves along the [001] direction to the $\mathrm{NNN} \mathrm{Ti}_{5 c}$ site. We never managed to observe dissociation in our relatively short runs for reasons discussed in Sec. VII A. This scenario, however, is not supported by DFT results, ${ }^{57}$ according to which $\mathrm{H}_{2} \mathrm{O}$ dissociation at $\mathrm{V}_{\mathrm{O}}$ corresponds to the lowest energy, both in $\mathrm{PBE}$ and $\mathrm{PBE}+U$. Note in passing that TB adsorption energies appear a factor of two larger than their DFT counterparts.
Rutile (100) is another surface for which there are DFT data with which to compare. Kamisaka and Yamashita ${ }^{53}$ report $E_{\text {ads }}^{\text {dis }}$ for water in the vacancy to be lower than $E_{\text {ads }}^{\text {mol }}$ at the regular $\mathrm{Ti}_{5 c}$ site on the ideal surface, which is in turn lower than $E_{\text {ads }}^{\text {dis }}$ on the ideal surface: $E_{\text {ads }}^{\text {dis }}($ reduced $)<$ $E_{\text {ads }}^{\text {mol }}$ (ideal) $<E_{\text {ads }}^{\text {dis }}$ (ideal). Our TB prediction is exactly the opposite: $E_{\text {ads }}^{\text {dis }}$ (reduced) $>E_{\text {ads }}^{\text {mol }}$ (ideal) $>E_{\text {ads }}^{\text {dis }}$ (ideal). As a matter of fact, TB results for the rutile (100) surface stand out from 
(001)

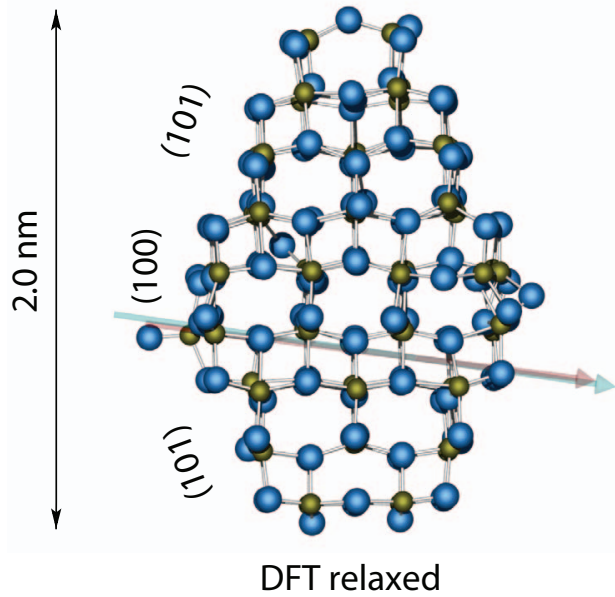

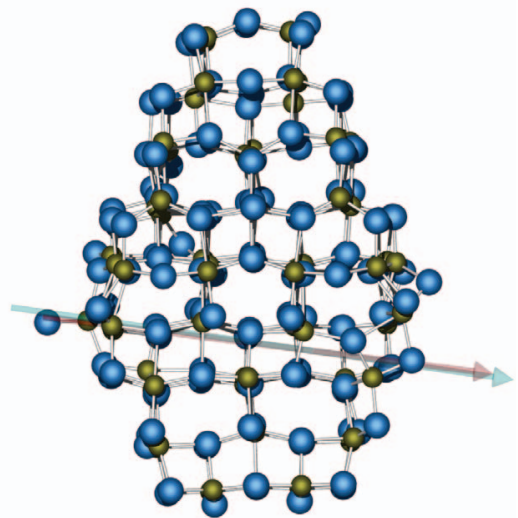

TB relaxed

FIG. 3. Equilibrium geometry of a 234 atom anatase cluster obtained with DFT GGA (PBE) ${ }^{63}$ (left panel) and with TB (right panel). Titanium and oxygen atoms are shown with green and blue spheres, respectively. Arrows (same on both panels) show the direction and relative magnitude of the spontaneous dipole which the clusters develop: 11.18 D in the PBE relaxed geometry (pink arrow) and 12.04 D in the TB relaxed geometry (light blue arrow).

those for other surfaces. For instance, molecular adsorption into $\mathrm{V}_{\mathrm{O}}$ results in significant relaxation of the top layer during which the $\mathrm{O}$ atom of adsorbed water molecule breaks its bond with one of the neighboring Ti atoms and tries to reach out to another $\mathrm{O}$ atom from the opposite row to form a $\mathrm{H}$-bond with it. This leads to a pronounced distortion in surrounding atoms resulting in a positive $E_{\text {ads }}^{\mathrm{mol}}$. It would be interesting to investigate the reduced rutile (100) surface with water using a more accurate approach, although there is, of course, a possibility that some of the TB predictions can be just an artefact of the present model.

For all other reduced surfaces listed in Table VI, TB predicts that water dissociation at an oxygen vacancy always leads to the lowest energy. This is true even for anatase (101) for which dissociation at the ideal surface is unfavorable. This is a plausible result, although more generally it seems that the good performance of the TB model observed for water adsorption at ideal surfaces somewhat worsens for reduced titania surfaces.

\section{ANATASE CLUSTERS}

There has been a surge of interest in titania clusters lately. $\mathrm{TiO}_{2}$ clusters are easy to prepare and they keep a good degree of crystallinity down to nanometer sizes. Nanosize samples are found to possess a number of attractive features, such as enhanced electrical properties and photocatalytic activity (see Refs. 68 and 69, and references therein). Expected enhancement of the surface reactivity of nanoclusters compared to macroscopic samples could be equally important. In this section we restrict ourselves to the anatase polymorph since this is the stable form of $\mathrm{TiO}_{2}$ clusters smaller than $14 \mathrm{~nm} .^{70}$

\section{A. Free standing clusters}

We begin by considering isolated stoichiometric clusters of anatase. A typical shape of a cluster shown in Fig. 3 for a 234 atom cluster and in Fig. 4 for a 1233 atom cluster has $\{101\},\{100\}$, and $\{001\}$ faces exposed. The equilibrium Wulff shape of anatase crystals according to DFT surface energies and that found in natural minerals has only $\{101\}$ and $\{001\}$ facets. ${ }^{3}$ However, the equilibrium shapes of small particles can differ from the Wulff shape since the Wulff construction neglects any energy associated with edges and corners. ${ }^{68}$ In particular, the $\{100\}$ facet was indeed detected in anatase powder. ${ }^{3}$

The geometry of the clusters shown in Figs. 3 and 4 was optimized using DFT GGA (PBE) ${ }^{63}$ and TB. The relaxed atomic positions significantly deviate from the initial ideal bulk positions (not shown), but in both cases the relaxation process ends up in similar geometries. This can be seen from

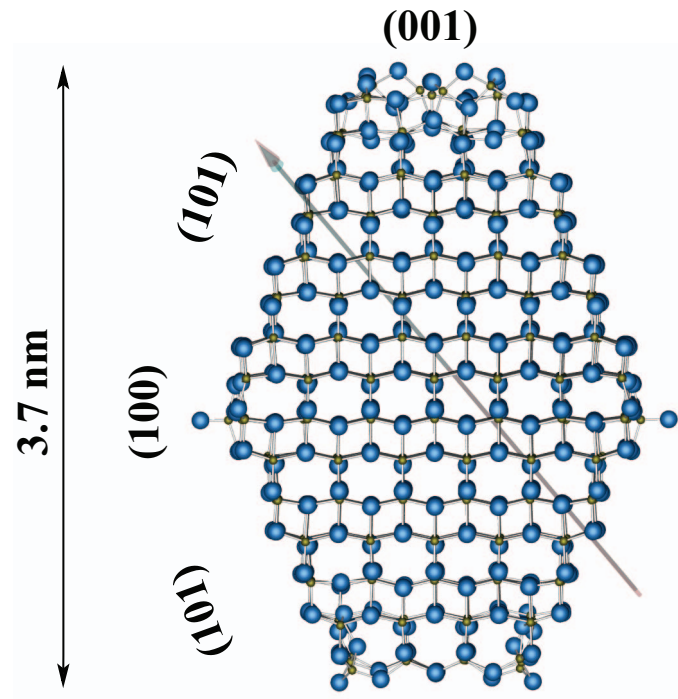

DFT and TB relaxed

FIG. 4. Same as Fig. 3 except for a bigger cluster (1233 atoms). The difference between geometries obtained by DFT GGA (PBE) ${ }^{63}$ and TB is indistinguishable on the figure scale, thus only one instance of the cluster is shown. Pink and light blue arrows correspond to dipoles 11.32 D (PBE-relaxed geometry) and 10.87 D (TB-relaxed geometry), respectively. 
the comparison of DFT relaxed (left panel) and TB relaxed (right panel) structures of the 234 atom cluster in Fig. 3. A relaxation of the 1233 atom cluster results in geometries practically indistinguishable on the plotted scale, therefore in Fig. 4 we show only the TB relaxed cluster.

A closer inspection of the TB results reveals that during atomistic relaxation clusters develop spontaneous dipole moments losing in the process the original symmetry of the cluster. The dipole was found both in the relaxed TB geometry and in the relaxed DFT geometry as indicated in Figs. 3 and 4 with blue and pink arrows, respectively. The loss of symmetry and spontaneous polarization of the clusters is an interesting effect which might not be completely surprising given the propensity of titania to ferroelectricity. Thus, a ferroelectric phase transition at negative pressure $p \simeq-4 \mathrm{GPa}$ was predicted by Montanari and Harrison ${ }^{71}$ on the basis of DFT analysis of phonon modes in rutile.

The magnitude of the spontaneous dipole in anatase, namely, about $10 \mathrm{D}$, is modest but not negligible-for comparison, the dipole of a water molecule in the gas phase is only $1.84 \mathrm{D}$. The formation of a spontaneous electrostatic dipole in water clusters with radius up to $3 \mathrm{~nm}$ was observed by Lever et $a l .{ }^{72}$ in DFT and force field simulations. It remains to be seen whether these effects are related.

\section{B. Anatase cluster with water}

We consider next the interaction of an anatase cluster and water molecules. There are a number of interesting questions one can immediately pose, such as: (i) Do the adsorption preferences of water molecules follow those at flat surfaces? (ii) Do water molecules dissociate better on clusters compared to planar semi infinite surfaces? (iii) What rôle is played by edge and corner atoms of a cluster? And ultimately, (iv) Are cluster surfaces more reactive than those of semi infinite crystals?

In order to obtain some insight into these questions we made MD simulations in a canonical ensemble at three temperatures: $T=300 \mathrm{~K}, 400 \mathrm{~K}$, and $500 \mathrm{~K}$. For our simulations we employ a 230 atom anatase cluster from Ref. 73. It has 78 $\mathrm{TiO}_{2}$ units and four oxygen vacancies, so it is a reduced titania sample. Contrary to the similar 234 atom stoichiometric cluster shown in Fig. 3, it does not have any "loose" oxygen atoms, such as those seen in the equatorial plane in Figs. 3 and 4, which makes it more suitable for MD simulations.

We first statically relaxed the cluster with 15 water molecules randomly placed around it until forces were smaller than $10^{-4} \mathrm{Ry} / \mathrm{Bohr}$. In the relaxed configuration, all $15 \mathrm{H}_{2} \mathrm{O}$ molecules absorb on the surface, forming bonds with $\mathrm{Ti}$ atoms. The average adsorption energy per molecule, $-0.82 \mathrm{eV}$, can be compared to those at planar surfaces $E_{\text {ads }}^{\mathrm{mol}}(101)=-0.81 \mathrm{eV}, E_{\mathrm{ads}}^{\mathrm{mol}}(100)=-0.70 \mathrm{eV}$, and $E_{\mathrm{ads}}^{\mathrm{mol}}(100)=-0.58 \mathrm{eV}$, whereas the corresponding vacancy adsorption energies are by $0.4 \mathrm{eV}$ lower (see Table VI). The HOMO-LUMO gap of the relaxed cluster, $2.0 \mathrm{eV}$, is significantly reduced compared to the band gap of bulk anatase, 3.35 $\mathrm{eV}$ in our model (see Table III). The static relaxation step was followed by $120-160$ ps of equilibration, after which we col-
TABLE VII. Temperature $T$, length of production run $\tau$, average proportion of water molecules adsorbed on facets (water/Ti ${ }_{5 c}$ ), on edges/corners of the cluster (water/ $\mathrm{Ti}_{4 c}$ ), and of unattached molecules (see Fig. 6 for the trajectory profiles). The last two lines show the average number of $\mathrm{H}$-bonds formed between two water molecules $\left\langle\mathrm{O}_{w}-\mathrm{H} \cdots \mathrm{O}_{w}\right\rangle$ and between a water molecule and titania's $\mathrm{O}$ atom $\left\langle\mathrm{O}_{w}-\mathrm{H} \cdots \mathrm{O}_{t}\right\rangle$ (see Fig. 7 for the respective histograms).

\begin{tabular}{lccc}
\hline \hline$T[\mathrm{~K}]$ & 300 & 400 & 500 \\
\hline length of MD run $\tau$ [ps] & 144 & 134 & 152 \\
$\left\langle n\left(\right.\right.$ water/ $\left.\left.\mathrm{Ti}_{5 c}\right)\right\rangle / n_{w}^{\text {tot }}$ & $45.87 \%$ & $53.08 \%$ & $42.61 \%$ \\
$\left\langle n\left(\right.\right.$ water $\left.\left./ \mathrm{Ti}_{4 c}\right)\right\rangle / n_{w}^{\text {tot }}$ & $52.99 \%$ & $45.98 \%$ & $33.34 \%$ \\
$\langle n($ unattached water $)\rangle / n_{w}^{\text {tot }}$ & 0 & $0.02 \%$ & $22.82 \%$ \\
$\left\langle\mathrm{O}_{w}-\mathrm{H} \cdots \mathrm{O}_{w}\right\rangle$ & 0.17 & 0.068 & 0.0066 \\
$\left\langle\mathrm{O}_{w}-\mathrm{H} \cdots \mathrm{O}_{t}\right\rangle$ & 20.99 & 20.69 & 13.13 \\
\hline \hline
\end{tabular}

lected data during the next $130-150 \mathrm{ps}$ of production run (see Table VII).

One of the snapshots, shown in Fig. 5, demonstrates a few typical features of molecular arrangement during MD simulations. A number of water molecules indeed attach to the

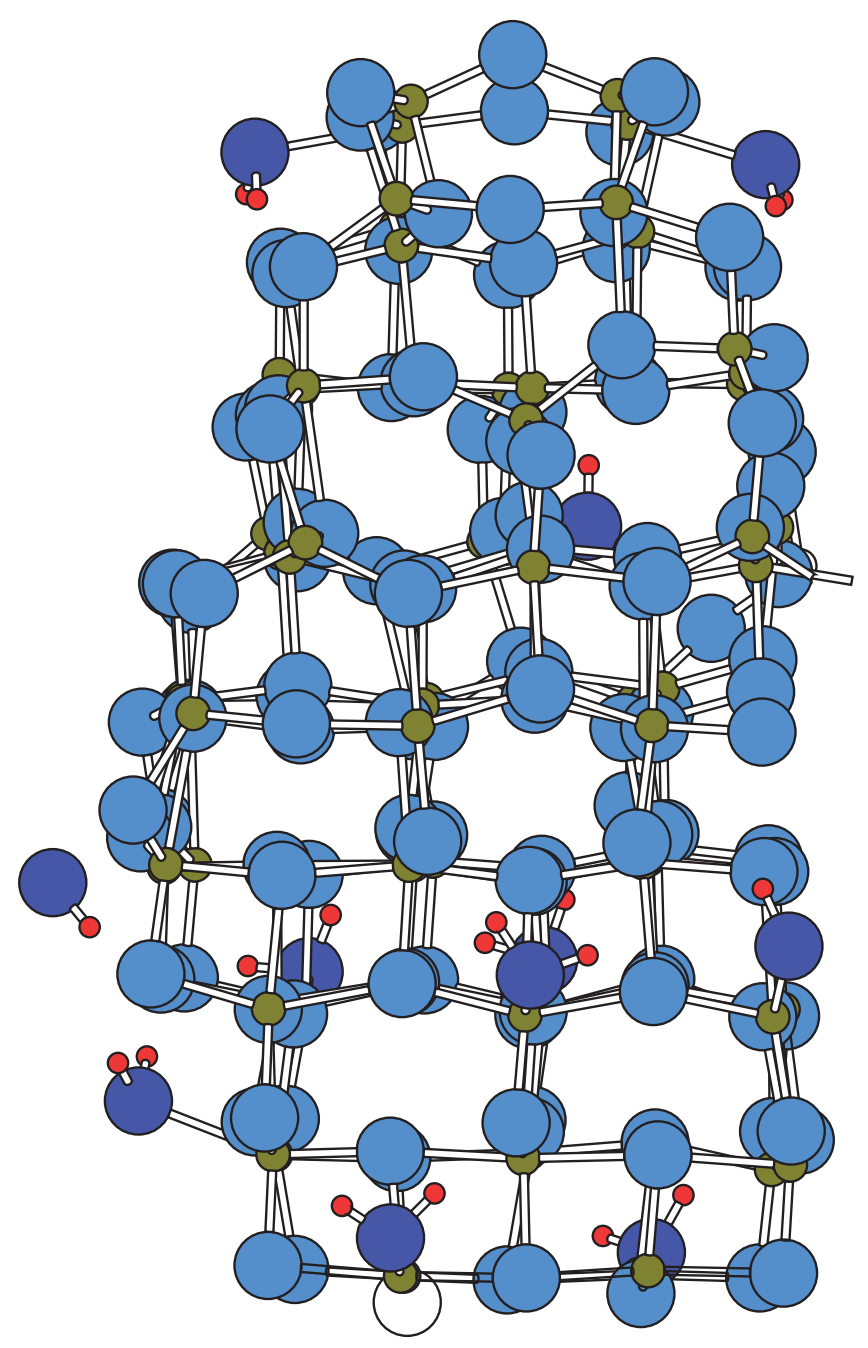

FIG. 5. A snapshot of MD simulation of the 230 atom anatase cluster with 15 water molecules at $T=500 \mathrm{~K}$. Green spheres are $\mathrm{Ti}$ atoms, red spheres are $\mathrm{H}$ atoms, blue and light blue spheres are $\mathrm{O}$ atoms of water and titania, respectively. $\mathrm{O}$ of course is the same species in both cases, it is painted differently only for convenience. 
(101) faces of the cluster which provide the lowest adsorption energy for planar surfaces, at least in our model. We also note five $\mathrm{H}_{2} \mathrm{O}$ molecules attached to the edge of the (001) face (two at the top, and three at the bottom of the cluster in Fig. 5) that lean toward the (101) facet and form H-bonds with $\mathrm{O}$ atoms on it. This configuration appears to be very stable, it persists in all three MD simulations with minor modifications. There are also two water molecules on the right hand side of the cluster (in the equatorial region) that form a $\mathrm{H}$-bonded chain $\mathrm{Ti}-\mathrm{O}_{w}-\mathrm{H} \cdots \mathrm{O}_{w}-\mathrm{H} \cdots \mathrm{O}_{t}$ (here and below $\mathrm{O}_{w}$ and $\mathrm{O}_{t}$ denote oxygen atoms of water and titania, respectively). This is a significantly less frequent event. And on the opposite side of the cluster, there is a water molecule moving along the surface and forming $\mathrm{H}$-bonds along its way.

A surprising result coming from our simulation is the fact that none of the $\mathrm{H}_{2} \mathrm{O}$ molecules dissociated in any of the $\mathrm{MD}$ runs. Even a molecule adsorbed on the (001) face, for which it takes only 3-6 ps to dissociate on an infinite (001) surface (see Sec. VII A), stays intact and either leans toward the (101) facet or diffuses away along the cluster. One of the reasons for high reactivity of the (001) surface of anatase towards water dissociation is a rather strained geometry of the surface layer. ${ }^{42}$ However, it is much easier to reduce such strain for atoms in a small cluster compared to a semi infinite crystal. Perhaps, that can explain the reluctance of water molecules to dissociate. More generally, there are indications that water should dissociate more readily on anatase clusters compared to macroscopic crystals (see Ref. 74 and references therein). Our simulations do not corroborate this expectation, at least not for a nanocluster as small as $2 \mathrm{~nm}$ in size.

We consider next the competition between adsorption onto facets, edges, and corners of a nanocrystallite. To formally distinguish between these sites we use the $\mathrm{O}$ coordination number of Ti atoms evaluated in the initial bulk truncated geometry of the cluster. Bulk atoms have 6 oxygen neighbors, surface atoms have 5, whereas edge and corner atoms have 4 neighbors each. We keep this classification of $\mathrm{Ti}$ atoms along all three $\mathrm{MD}$ trajectories, assuming that $\mathrm{Ti}^{-} \mathrm{O}_{t}$ bonds do not cleave or reform. ${ }^{75}$

The relative number of adsorbed water molecules taken along the trajectories is shown in Fig. 6. There are $12 \mathrm{Ti}_{4 c}$ atoms and $40 \mathrm{Ti}_{5 c}$ atoms in the cluster. However, the $T=$ $300 \mathrm{~K}$ results show that the adsorbed molecules split almost equally between two types of sites, with the $\mathrm{Ti}_{4 c}$ even having some advantage (53\% vs. $46 \%$ according to Table VII). This indicates that edges and corners are more favorable than the (101), (100), and (001) facets. In the $T=400 \mathrm{~K}$ simulation, this picture changes to its opposite: now $46 \%$ water molecules occupy $\mathrm{Ti}_{4 c}$ sites and $53 \%$ molecules adsorb on $\mathrm{Ti}_{5 c}$. This is a clear manifestation of the entropic contribution to the free energy since $40 \mathrm{Ti}_{5 c}$ sites have larger configurational entropy than $12 \mathrm{Ti}_{4 c}$ sites. If the trend continues, one would expect occupations to tend to $23 \%$ and $77 \%$ in the hypothetical high temperature limit. However, at $T=500 \mathrm{~K}$ both occupations decrease to $33 \%$ and $43 \%$, respectively, because at this temperature the onset of water evaporation is observed on the simulation time scale. By the end of 150 ps of equilibration, the $500 \mathrm{~K}$ system has already lost three out of 15 water molecules. A fourth molecule flew away after $90 \mathrm{ps}$ of the production run
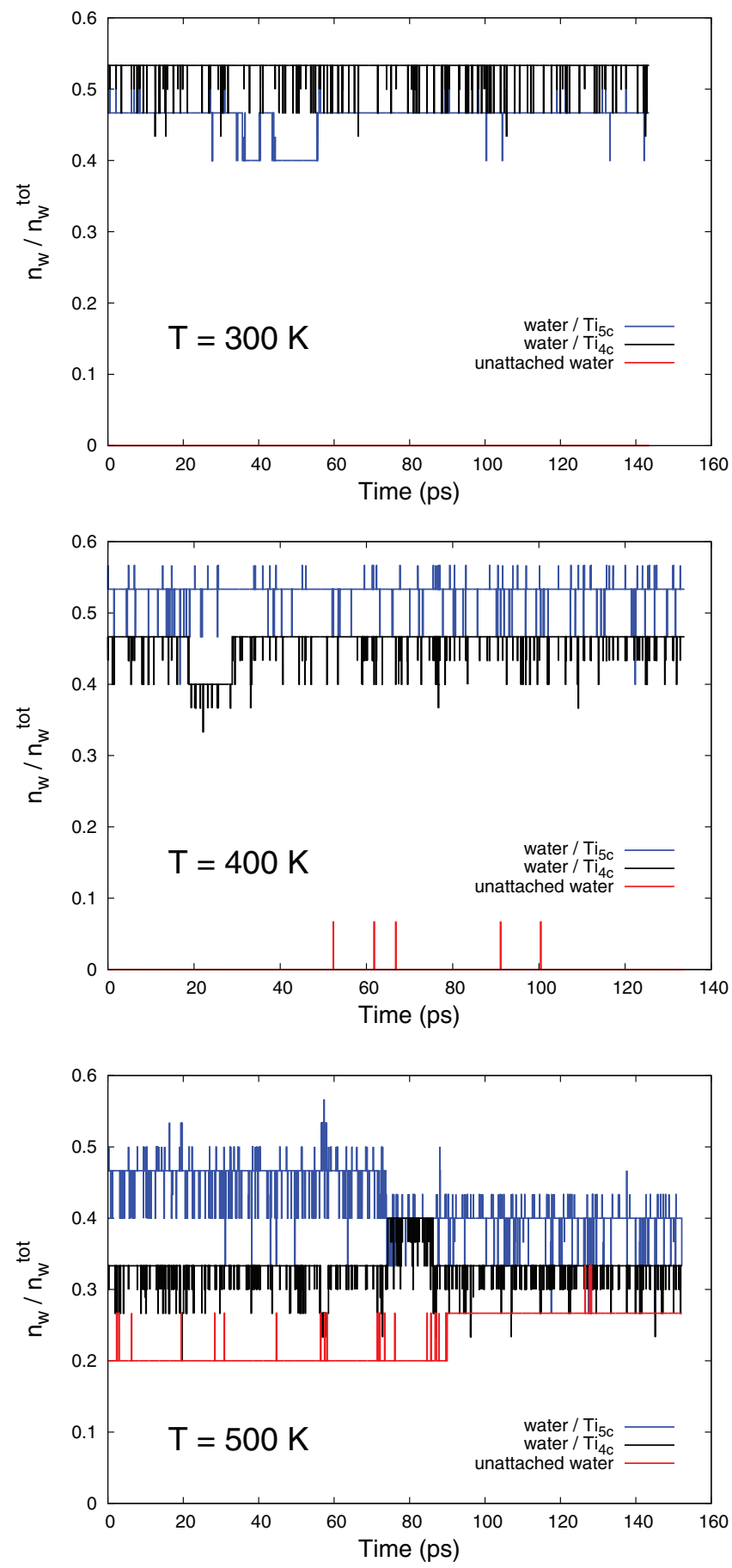

FIG. 6. Fraction of water molecules, $n_{w} / n_{w}^{\text {tot }}$ (where $n_{w}^{\text {tot }}=15$ ) adsorbed on 5-fold coordinated titanium atoms $\mathrm{Ti}_{5 c}$ (blue line), 4-fold coordinated titanium atoms $\mathrm{Ti}_{4 c}$ (black line), and of unattached molecules (red line) collected along the trajectory of three NVT simulations at $300 \mathrm{~K}$ (top panel), $400 \mathrm{~K}$ (middle panel), and $500 \mathrm{~K}$ (bottom panel). See Table VII for the average quantities.

(see red line in Fig. 6). Overall, in the adsorption behavior we clearly see an interplay between potential energy and entropic contribution, affected by adsorbate evaporation at higher temperatures.

Finally, we look at the formation of hydrogen bonds in the system. Do water molecules prefer to form H-bonds with the substrate or with each other? The answer is the former, as is clear from Table VII and Fig. 7. This is not because the 

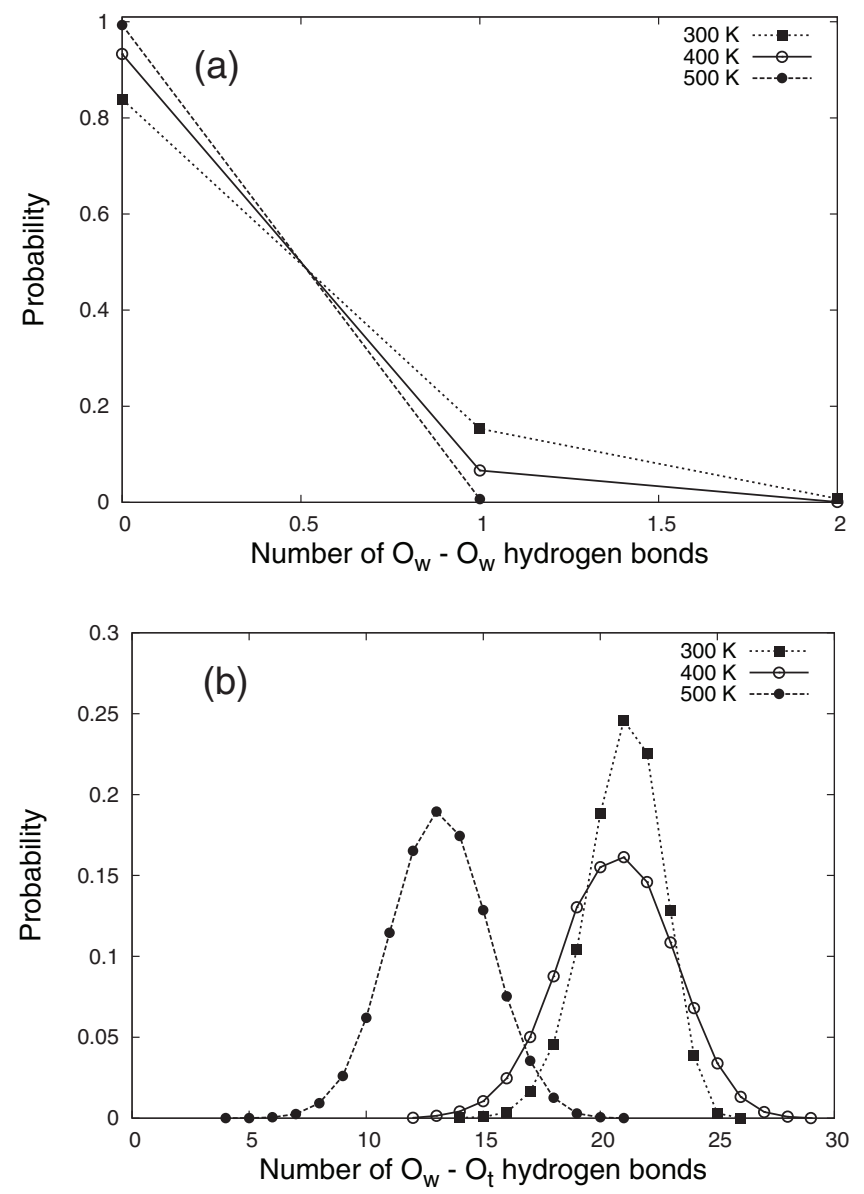

FIG. 7. Histograms showing the number of hydrogen bonds (a) between two water molecules and (b) between a water molecule and titania's oxygen atom $\left(\mathrm{O}_{t}\right)$. See Table VII for the average number of $\mathrm{H}$-bonds.

$\mathrm{O}_{w}-\mathrm{H} \cdots \mathrm{O}_{t}$ bond is much stronger than the $\mathrm{O}_{w}-\mathrm{H} \cdots \mathrm{O}_{w}$ bond but rather because the $\mathrm{O}_{w}-\mathrm{H} \cdots \mathrm{O}_{t}$ bonds are formed in addition to the adsorption onto Ti sites (see Fig. 5), so it is in fact the competition between the $\mathrm{Ti}-\mathrm{O}_{w}-\mathrm{H} \cdots \mathrm{O}_{t}$ and $\mathrm{O}_{w}-\mathrm{H} \cdots \mathrm{O}_{w}$ bonds. Not surprisingly, only a small fraction of frames have at least one water-water H-bond $(15 \%$ at $300 \mathrm{~K}, 7 \%$ at $400 \mathrm{~K}$, and less than $1 \%$ at $500 \mathrm{~K}$, see Fig. 7(a)).

$\mathrm{O}_{w}-\mathrm{O}_{t}$ bonds, on the other hand, are formed frequently, with more than one bond per molecule on average. With temperature increasing, one would expect the Gaussian-type distribution of H-bonds, such as those shown in Fig. 7(b), to widen. This is indeed the case for $T=300 \mathrm{~K}$ and $T=400 \mathrm{~K}$. The $T=500 \mathrm{~K}$ curve is significantly shifted to the left due to the loss of some water molecules. In addition, the distribution appears less spread than the one at $T=400 \mathrm{~K}$, for which we do not have any clear explanation at the moment.

\section{DISCUSSION AND CONCLUSIONS}

We have described a lengthy and complicated fitting procedure leading to a multi-parameter tight binding model. Nevertheless, it is remarkable that the resulting model is able to faithfully reproduce a number of non trivial properties of $\mathrm{TiO}_{2}$ that are normally controversial and uncertain even at the level of DFT and quantum chemistry calculations. In addition by combining and merging this model with our parallel work on water, we are able to make predictions about the reactive behavior of water at $\mathrm{TiO}_{2}$ surfaces, in simulations that are beyond the capability of other methods due to the large length and time scales involved. It is due to this success as well as that reported in Papers I and $\mathrm{II}^{1,2}$ that we can claim to have created a "universal" TB scheme that amounts essentially to a computational tool that is freely available to the community. ${ }^{27}$ In fact it is worth recalling some of the phenomena that we are able to describe with a single parameterization of the oxygen atom: these include, the $\mathrm{O}-\mathrm{O}$ radial distribution function in water and an explanation of the "fifth neighbour"; 2 proton transfer and enolization in aqueous solvent ${ }^{1}$ transferable and quantitatively accurate description of single and double carbon-oxygen bonds; ${ }^{1}$ the dissociation of water on $\mathrm{TiO}_{2}$ surfaces-both stoichiometric and reduced.

We must emphasize that our approach is radically different compared to recent TB models. ${ }^{76-79}$ Those authors take the view that an optimal TB parameter set may be discovered by explicit DFT calculations or the fitting of bond integrals and on-site energies to directly calculated integrals over projections from Kohn-Sham orbitals. This is of course an attractive approach, but in our view this leaves little room to move in the parameter space once the more fundamental parameters are firmly established. In particular the volume or bond length dependence of the on-site energies is implicit in any DFT calculation but is absent in almost all TB models. In addition the pair potentials are much more difficult to extract from a DFT calculation, except by simple subtraction of the total and band energies. As we have shown in this series of papers, careful negotiation is needed between parameter sets in order to obtain a universal model. Furthermore the nature of the hydrogen bond, which is particularly elusive, needs to be granted particular attention and is at any event beyond the reach of ab initio DFT.

In conclusion, we have demonstrated a TB model for $\mathrm{TiO}_{2}$ and presented detailed results of simulations of both the infinite solid, semi infinite solid, and nanocrystalline free standing clusters. In each case we have made comparisons with established and speculative results of experiments and more accurate calculations. We have discussed the question of water adsorption at both stoichiometric and reduced surfaces and described conditions under which it would be expected that the water will dissociate. Finally, we use the model to explore the adsorption of water on anatase nanoparticles at different temperatures and demonstrate the interplay between adsorption at facets, facet edges, and corners, as well as between the potential energy and configurational entropy.

This work will be followed by large scale simulations probably leading to new predictions of the behavior of water at $\mathrm{TiO}_{2}$. In the near future we expect to be able to model an entire process in catalysis at nanoparticle surfaces.

\section{ACKNOWLEDGMENTS}

We would like to thank Matthew Neurock for bringing the water-anatase clusters system to our attention. We thank Joost VandeVondele for sharing with us the structure of DFTrelaxed clusters discussed in Sec. VIII A. We are also grateful 
to Ya Zhou and Kristen A. Fichthorn for sending us atomic coordinates of reduced anatase clusters from Ref. 73 which we used in Sec. VIII B. A.Y.L. appreciates Myrta Grüning's comment on band gap calculations with "beyond DFT" approaches. Queen's University Belfast is acknowledged for the provision of computational resources on the DELL computer cluster. The work is a part of the CASTech catalysis project supported by the EPSRC through Grant No. EP/G012156/1.

${ }^{1}$ T. J. Sheppard, A. Y. Lozovoi, D. L. Pashov, J. J. Kohanoff, and A. T. Paxton, J. Chem. Phys. 141, 044503 (2014).

${ }^{2}$ A. Y. Lozovoi, T. J. Sheppard, D. L. Pashov, J. J. Kohanoff, and A. T. Paxton, J. Chem. Phys. 141, 044504 (2014).

${ }^{3}$ U. Diebold, Surf. Sci. Rep. 48, 53 (2003).

${ }^{4}$ C. Sun, L.-M. Liu, A. Selloni, G. Q. Lu, and S. C. Smith, J. Mater. Chem. 20, 10319 (2010).

${ }^{5}$ C. L. Pang, R. Lindsay, and G. Thornton, Chem. Soc. Rev. 37, 2328 (2008).

${ }^{6}$ C. L. Pang, R. Lindsay, and G. Thornton, Chem. Rev. 113, 3887 (2013).

${ }^{7}$ L. Goodwin, A. J. Skinner, and D. G. Pettifor, Europhys. Lett. 9, 701 (1989).

${ }^{8}$ M. W. Finnis, A. T. Paxton, M. Methfessel, and M. van Schilfgaarde, Phys. Rev. Lett. 81, 5149 (1998).

${ }^{9}$ S. Fabris, A. T. Paxton, and M. W. Finnis, Phys. Rev. B 63, 941011 (2001).

${ }^{10} \mathrm{M}$. W. Finnis, Interatomic Forces in Condensed Matter (Oxford University Press, Oxford, UK, 2003).

${ }^{11}$ A. T. Paxton, in Multiscale Simulation Methods in Molecular Sciences, NIC Series Vol. 42, edited by J. Grotendorst, N. Attig, S. Blügel, and D. Marx (Institute for Advanced Simulation, Forschungszentrum Julich, 2009), pp. 145-174. Also available on-line at http://webarchiv.fz-juelich.de/ nic-series/volume42/volume42.html.

${ }^{12} \mathrm{P}$. A. Cox, Transition Metal Oxides: An Introduction to Their Electronic Structure and Properties (Oxford University Press, Oxford, UK, 2010).

${ }^{13}$ W. A. Harrison, Electronic Structure and the Properties of Solids, the Physics of the Chemical Bond (W. H. Freeman and Company, San Francisco, 1980).

${ }^{14}$ A. T. Paxton and J. J. Kohanoff, J. Chem. Phys. 134, 044130 (2011).

${ }^{15}$ S. Fabris, A. T. Paxton, and M. W. Finnis, Phys. Rev. B 61, 6617 (2000).

${ }^{16} \mathrm{~N}$. Benedek, K. Johnston, and A. T. Paxton, unpublished results.

${ }^{17}$ S. Fabris, A. T. Paxton, and M. W. Finnis, Acta Mater. 50, 5171 (2002).

${ }^{18}$ H.-P. Schwefel, Numerische Optimierung von Computer-Modellen mittels der Evolutionsstrategie, Interdisciplinary Systems Research Vol. 26 (Birkhäuser, Basle, 1977).

${ }^{19}$ H.-P. Schwefel, Evolution and Optimum Seeking (Sixth Generation Computer Technologies) (Wiley, New York, 1995).

${ }^{20}$ J. K. Burdett, T. Hughbanks, G. J. Miller, J. W. Richardson, and J. V. Smith, J. Am. Chem. Soc. 109, 3639 (1987).

${ }^{21}$ J. K. Dewhurst and J. E. Lowther, Phys. Rev. B 54, R3673 (1996)

${ }^{22}$ L.-C. Ming and M. H. Manghnani, J. Geophys. Res.: Solid Earth 84, 4777, doi:10.1029/JB084iB09p04777 (1979).

${ }^{23}$ T. Arlt, M. Bermejo, M. A. Blanco, L. Gerward, J. Z. Jiang, J. S. Olsen, and J. M. Recio, Phys. Rev. B 61, 14414 (2000).

${ }^{24}$ J. Pascual, J. Camassel, and H. Mathieu, Phys. Rev. Lett. 39, 1490 (1977).

${ }^{25}$ H. Tang, H. Berger, P. Schmid, F. Lévy, and G. Burri, Solid State Commun. 87, 847 (1993)

${ }^{26}$ S. J. Smith, R. Stevens, S. Liu, G. Li, A. Navrotsky, J. Boerio-Goates, and B. F. Woodfield, Am. Miner. 94, 236 (2009).

${ }^{27}$ Empirical tight binding (TBE) and full potential LMTO computer programs (LMF) are parts of the LM electronic structure package (http://www.lmsuite.org).

${ }^{28}$ H. J. Monkhorst and J. D. Pack, Phys. Rev. B 13, 5188 (1976).

${ }^{29}$ G. J. Martyna, M. E. Tuckerman, D. J. Tobias, and M. L. Klein, Mol. Phys. 87, 1117 (1996).

${ }^{30}$ J. Muscat, V. Swamy, and N. M. Harrison, Phys. Rev. B 65, 224112 (2002).

${ }^{31}$ F. Labat, P. Baranek, C. Domain, C. Minot, and C. Adamo, J. Chem. Phys. 126, 154703 (2007).

${ }^{32}$ L. Chiodo, J. M. Garcia-Lastra, A. Iacomino, S. Ossicini, J. Zhao, H. Petek, and A. Rubio, Phys. Rev. B 82, 045207 (2010).

${ }^{33}$ M. Landmann, E. Rauls, and W. G. Schmidt, J. Phys.: Condens. Matter 24, 195503 (2012)
${ }^{34}$ G. Dolgonos, B. Aradi, N. H. Moreira, and T. Frauenheim, J. Chem. Theory Comput. 6, 266 (2010).

${ }^{35}$ F. Labat, P. Baranek, and C. Adamo, J. Chem. Theory Comput. 4, 341 (2008).

${ }^{36}$ M. Lazzeri, A. Vittadini, and A. Selloni, Phys. Rev. B 63, 155409 (2001).

${ }^{37}$ M. Lazzeri, A. Vittadini, and A. Selloni, Phys. Rev. B 65, 119901 (2002) [Erratum].

${ }^{38}$ A. Kiejna, T. Pabisiak, and S. W. Gao, J. Phys.: Condens. Matter 18, 4207 (2006).

${ }^{39}$ P. M. Kowalski, B. Meyer, and D. Marx, Phys. Rev. B 79, 115410 (2009).

${ }^{40}$ L. Mino, G. Spoto, S. Bordiga, and A. Zecchina, J. Phys. Chem. C 117, 11186 (2013).

${ }^{41}$ T. R. Esch, I. Gadaczek, and T. Bredow, Appl. Surf. Sci. 288, 275 (2014).

${ }^{42}$ X.-Q. Gong and A. Selloni, J. Phys. Chem. B 109, 19560 (2005).

${ }^{43}$ A. Marmier, A. Lozovoi, and M. W. Finnis, J. Eur. Ceram. Soc. 23, 2729 (2003)

${ }^{44}$ R. Lindsay, A. Wander, A. Ernst, B. Montanari, G. Thornton, and N. M. Harrison, Phys. Rev. Lett. 94, 246102 (2005).

${ }^{45}$ A. Y. Lozovoi, A. Alavi, and M. W. Finnis, Phys. Rev. Lett. 85, 610 (2000)

${ }^{46}$ H. Cheng and A. Selloni, J. Chem. Phys. 131, 054703 (2009).

${ }^{47}$ T. Pabisiak and A. Kiejna, Solid State Commun. 144, 324 (2007).

${ }^{48}$ P. Scheiber, M. Fidler, O. Dulub, M. Schmid, U. Diebold, W. Hou, U. Aschauer, and A. Selloni, Phys. Rev. Lett. 109, 136103 (2012).

${ }^{49}$ A. Vittadini, M. Casarin, and A. Selloni, Theor. Chem. Acc. 117, 663 (2007)

${ }^{50}$ M. B. Hugenschmidt, L. Gamble, and C. T. Campbell, Surf. Sci. 302, 329 (1994)

${ }^{51}$ M. A. Henderson, Surf. Sci. 355, 151 (1996).

${ }^{52}$ D. Brinkley, M. Dietrich, T. Engel, P. Farrall, G. Gantner, A. Schafer, and A. Szuchmacher, Surf. Sci. 395, 292 (1998).

${ }^{53}$ H. Kamisaka and K. Yamashita, Surf. Sci. 601, 4824 (2007).

${ }^{54}$ P. J. D. Lindan and C. Zhang, Phys. Rev. B 72, 075439 (2005).

${ }^{55}$ A. Tilocca, C. Di Valentin, and A. Selloni, J. Phys. Chem. B 109, 20963 (2005).

${ }^{56}$ W. Zhang, J. Yang, Y. Luo, S. Monti, and V. Carravetta, J. Chem. Phys. 129, 064703 (2008).

${ }^{57}$ M. F. Camellone, P. M. Kowalski, and D. Marx, Phys. Rev. B 84, 035413 (2011).

${ }^{58}$ Y. He, A. Tilocca, O. Dulub, A. Selloni, and U. Diebold, Nat. Mater. 8, 585 (2009).

${ }^{59}$ G. S. Herman, Z. Dohnálek, N. Ruzycki, and U. Diebold, J. Phys. Chem. B 107, $2788(2003)$.

${ }^{60}$ Z. Zhao, Z. Li, and Z. Zou, J. Phys. Chem. C 116, 7430 (2012).

${ }^{61}$ A. T. Paxton and L. Thiên-Nga, Phys. Rev. B 57, 1579 (1998).

${ }^{62} \mathrm{We}$ do not have the $\mathrm{H}_{2}$ molecule either since we neglect any attraction between hydrogen atoms, otherwise we could have estimated the chemical potential of $\mathrm{O}, \mu_{\mathrm{O}}$, as the difference between $\mathrm{H}_{2} \mathrm{O}$ and $\mathrm{H}_{2}$. The best estimation we could make is to use experimental energy of $\mathrm{O}_{2}$ dissociation (with vibrations removed), $5.230 \mathrm{eV}$ [Y. Zhang and W. Yang, Phys. Rev. Lett. 80, 890 (1998)], and promotion energy of oxygen atom from the triplet to singlet state, $2.399 \mathrm{eV}$ (CCSD, our own calculation) to arrive at the absolute vacancy formation energy on rutile $(110) E^{f}\left(\mathrm{~V}_{\mathrm{O}}\right)=2.39 \mathrm{eV}$.

${ }^{63} \mathrm{~J}$. VandeVondele, private communication (2013).

${ }^{64}$ A. Fujishima and K. Honda, Nature (London) 238, 37 (1972).

${ }^{65}$ L. E. Walle, A. Borg, P. Uvdal, and A. Sandell, Phys. Rev. B 80, 235436 (2009).

${ }^{66}$ D. A. Duncan, F. Allegretti, and D. P. Woodruff, Phys. Rev. B 86, 045411 (2012).

${ }^{67}$ L. E. Walle, D. Ragazzon, A. Borg, P. Uvdal, and A. Sandell, Surf. Sci. 621, 77 (2014).

${ }^{68}$ D. R. Hummer, J. D. Kubicki, P. R. C. Kent, J. E. Post, and P. J. Heaney, J. Phys. Chem. C 113, 4240 (2009).

${ }^{69}$ M. A. Henderson, Surf. Sci. Rep. 66, 185 (2011).

${ }^{70}$ H. Zhang and J. F. Banfield, J. Mater. Chem. 8, 2073 (1998).

${ }^{71}$ B. Montanari and N. M. Harrison, J. Phys.: Condens. Matter 16, 273 (2004).

${ }^{72}$ G. Lever, D. J. Cole, N. D. M. Hine, P. D. Haynes, and M. C. Payne, J. Phys.: Condens. Matter 25, 152101 (2013).

${ }^{73}$ Y. Zhou and K. A. Fichthorn, J. Phys. Chem. C 116, 8314 (2012).

${ }^{74}$ A. Selloni, Nat. Mater. 7, 613 (2008).

${ }^{75}$ The definition of bonds in our study is based on the position of the first minimum in radial distribution functions for respective species, which are: $3.4 \AA$ for $\mathrm{Ti}-\mathrm{Ti}, 2.7 \AA$ for $\mathrm{Ti}-\mathrm{O}_{t}, 2.9 \AA$ for $\mathrm{Ti}-\mathrm{O}_{w}, 3.6 \AA$ for $\mathrm{O}_{t}-\mathrm{O}_{t}$, and 
$3.2 \AA$ for both $\mathrm{O}_{t}-\mathrm{O}_{w}$ and $\mathrm{O}_{w}-\mathrm{O}_{w}$. The $\mathrm{O}_{t}-\mathrm{O}_{w}$ and $\mathrm{O}_{w}-\mathrm{O}_{w}$ distances in particular are used in the definition of water-water and water-titania $\mathrm{H}$ bonds together with the $30^{\circ}$ criterion for the $\widehat{\mathrm{HOO}}$ angle [A. Luzar and D. Chandler, Phys. Rev. Lett. 76, 928 (1996)].

${ }^{76} \mathrm{~S}$. Sanna, B. Hourahine, T. Gallauner, and T. Frauenheim, J. Phys. Chem. 111, 5665 (2007).
${ }^{77}$ G. K. H. Madsen, E. J. McEniry, and R. Drautz, Phys. Rev. B 83, 184119 (2011).

${ }^{78}$ A. Urban, M. Reese, M. Mrovec, C. Elsässer, and B. Meyer, Phys. Rev. B 84, 155119 (2011)

${ }^{79}$ N. Hatcher, G. K. Madsen, and R. Drautz, Phys. Rev. B 86, 155115 (2012). 